\title{
Quantitative analysis of proteome extracted from barley crowns grown under different drought conditions
}

\author{
Pavel Vitámvás ${ }^{1 *}$, Milan O. Urban ${ }^{1}, Z^{2}$ bynek Škodáček ${ }^{1}$, Klára Kosová ${ }^{1}$, Iva Pitelková ${ }^{1}$, \\ Jan Vitámvás ${ }^{1,2}$, Jenny Renaut ${ }^{3}$ and Ilja T. Prášil ${ }^{1}$ \\ 1 Division of Crop Genetics and Breeding, Plant Stress Biology and Biotechnology, Crop Research Institute, Prague, Czech \\ Republic, ${ }^{2}$ Faculty of Forestry and Wood Sciences, Czech University of Life Sciences Prague, Prague, Czech Republic, \\ ${ }^{3}$ Department of Environmental Research and Innovation, Luxembourg Institute of Science and Technology, Belvaux, \\ Luxembourg
}

OPEN ACCESS

Edited by:

Ganesh Kumar Agrawal,

Research Laboratory for

Biotechnology and Biochemistry,

Nepal

Reviewed by:

Tiago Santana Balbuena,

State University of São Paulo, Brazil

Niranjan Chakraborty,

National Institute of Plant Genome

Research, India

*Correspondence:

Pavel Vitámvás,

Division of Crop Genetics and Breeding, Plant Stress Biology and

Biotechnology, Crop Research Institute, Drnovská 507/73, 16106

Prague 6, Czech Republic vitamvas@vurv.cz

Specialty section:

This article was submitted to

Plant Proteomics,

a section of the journal

Frontiers in Plant Science

Received: 27 February 2015

Accepted: 15 June 2015

Published: 30 June 2015

Citation:

Vitámvás $P$, Urban MO, Škodáček $Z$, Kosová K, Pitelková I, Vitámvás J,

Renaut J and Práśil IT (2015)

Quantitative analysis of proteome extracted from barley crowns grown under different drought conditions.

Front. Plant Sci. 6:479.

doi: 10.3389/fp/s.2015.00479
Barley cultivar Amulet was used to study the quantitative proteome changes through different drought conditions utilizing two-dimensional difference gel electrophoresis (2D-DIGE). Plants were cultivated for 10 days under different drought conditions. To obtain control and differentially drought-treated plants, the soil water content was kept at 65,35 , and $30 \%$ of soil water capacity (SWC), respectively. Osmotic potential, water saturation deficit, ${ }^{13} \mathrm{C}$ discrimination, and dehydrin accumulation were monitored during sampling of the crowns for proteome analysis. Analysis of the 2D-DIGE gels revealed 105 differentially abundant spots; most were differentially abundant between the controls and drought-treated plants, and 25 spots displayed changes between both drought conditions. Seventy-six protein spots were successfully identified by tandem mass spectrometry. The most frequent functional categories of the identified proteins can be put into the groups of: stress-associated proteins, amino acid metabolism, carbohydrate metabolism, as well as DNA and RNA regulation and processing. Their possible role in the response of barley to drought stress is discussed. Our study has shown that under drought conditions barley cv. Amulet decreased its growth and developmental rates, displayed a shift from aerobic to anaerobic metabolism, and exhibited increased levels of several protective proteins. Comparison of the two drought treatments revealed plant acclimation to milder drought (35\% SWC); but plant damage under more severe drought treatment (30\% SWC). The results obtained revealed that cv. Amulet is sensitive to drought stress. Additionally, four spots revealing a continuous and significant increase with decreasing SWC (UDP-glucose 6-dehydrogenase, glutathione peroxidase, and two non-identified) could be good candidates for testing of their protein phenotyping capacity together with proteins that were significantly distinguished in both drought treatments.

Keywords: Hordeum vulgare, crown, drought, proteomics, phenotyping candidate

\section{Introduction}

Drought, which significantly reduces agricultural production, represents the most severe abiotic stress worldwide. There are several definitions of drought based on different views and constraints such as meteorological drought, physiological drought, etc. (Lawlor, 2013). Physiological drought 
represents a discrepancy between plant water uptake and water release, resulting in water deficit and cellular dehydration. Cellular dehydration induces profound alterations in plant cell structure and metabolism, aimed at minimizing the harmful effects of the drought. Drought induces several processes in plant cells including: increased levels of abscisic acid, the levels of some metabolites such as proline, induction of stress-regulated genes, and changes in the activity of some proteins (Kosová et al., 2011). Proteins play an important role in plant adjustment to water deficit since they are directly involved in plant cell structure and metabolism. Stress-induced proteins include regulatory proteins (e.g., transcription factors, protein kinases, protein phosphatases, signaling proteins), as well as effector proteins directly involved in stress tolerance acquisition (such as chaperones), late embryogenesis abundant (LEA) proteins (such as dehydrins), mRNA-binding proteins, water channel proteins, osmolyte synthesis enzymes, components of protein biosynthesis and degradation, cytoskeletal proteins, and detoxification enzymes (Kosová et al., 2011). Dehydrins belong to the LEA protein family, and are induced by low-temperature, drought, and salinity stress in plants (Kosová et al., 2014). Moreover, in our previous studies, the accumulation of dehydrins was used to correlate cereal genotypes with different tolerance levels to abiotic stresses (Vítámvás et al., 2007, 2010; Ganeshan et al., 2008; Kosová et al., 2008, 2010, 2012, 2013; Vítámvás and Prášil, 2008; Holková et al., 2009). However, the resulting level of abiotic stress tolerance also depends on components of plant stress response other than dehydrin accumulation; therefore, detailed knowledge about the stress-dependent proteome changes is necessary.

Plant response to drought can be very diverse, depending on the severity of stress and stress timing with respect to the plant's developmental phase. Plant stress response represents a dynamic process where several phases with unique proteome compositions can be distinguished (Levitt, 1980; Larcher, 2003; Kosová et al., 2011). The initial phases of stress response (alarm and acclimation phases) usually reveal more profound differences in proteome composition (with respect to the controls), compared to later phases of stress (tolerance phase) when a novel homeostasis between plant and environment has already been established.

Barley (Hordeum vulgare) is a relatively drought- and salttolerant cereal crop having originated in semi-arid regions of the Middle East. Recent publication of the complete barley genome sequence (The International Barley Genome Sequencing Consortium, 2012) has significantly improved the accuracy of protein sequence identification, thus enhancing the reliability of the proteomic results. Therefore, barley represents an ideal model for investigation of crop proteome response to several stress factors. Several studies have compared barley's response to drought at the transcript level (Ueda et al., 2004; Talame et al., 2007; Tommasini et al., 2008; Guo et al., 2009). However, the accumulation of transcripts only gives a rough estimation of the protein accumulation due to translational regulations and post-translational modification or degradation of the protein (Kosová et al., 2011). Barley proteome response of barley organs to drought has only been studied by a few researchers (leaf and root-Wendelboe-Nelson and Morris, 2012; leaf-Ashoub et al., 2013; leaf-Ghabooli et al., 2013; shoot-Kausar et al., 2013). Moreover, until now, no study of changes in barley crown proteome under drought was performed. In cereals, it has been shown that survival of a plant depends on the survival of its crown tissues (e.g., Tanino and McKersie, 1985), since crowns contain both root and shoot meristems, and thus are crucial for both root and shoot regeneration after stress treatment. Due to a lack of RuBisCO, many more protein spots could be detected and analyzed by the gel-based proteomic approach than from leaf samples (e.g., Hlaváčková et al., 2013).

The aim of the study was to investigate the response of spring barley Amulet to drought at two different intensities of drought stress, characterized by different levels of soil water capacity (SWC): 35\% SWC-mild drought-D1; 30\% SWCsevere drought-D2; and $65 \%$ SWC-control-C. Therefore, our study had the following partial goals: (1) To investigate barley cv. Amulet response to two differential levels of drought characterized by plant water relationships (water saturation deficit, osmotic potential), the effect of drought on photosynthesis and water use efficiency characterized by ${ }^{13} \mathrm{C}$ discrimination, and total proteome analysis by two-dimensional difference gel electrophoresis (2D-DIGE). (2) To compare the effects of two intensities of drought stress on barley plants with respect to the severity of stress impacts on the plant characteristics described above. Detection and identification of barley crown proteins revealing a differential abundance between control and drought, as well as between the two drought treatments associated with a determination of basic plant water characteristics; enabling us to distinguish common processes underlying barley's response to drought as well as specific processes differentiating the two drought intensities.

\section{Materials and Methods}

\section{Plant Materials and Growth Conditions}

The experiments were performed on spring barley cv. Amulet (Hordeum vulgare L.) obtained from the Gene Bank of the Crop Research Institute in Prague (Czech Republic). Amulet is an important spring malting barley cultivar grown in the Czech Republic (see detailed characterization and pedigree at http:// genbank.vurv.cz/genetic/resources/asp2/default_a.htm). The seeds were germinated at $20^{\circ} \mathrm{C}$ for 3 days in darkness. After germination, the seedlings ( 9 plants per $8 \mathrm{~L}$ pot) were grown in soil (a mixture of Alfisol with manure and sand, 6:2:1) under controlled conditions in a greenhouse $\left(20^{\circ} \mathrm{C}\right.$ with $16 / 8 \mathrm{~h}$ of light/dark provided by a high-pressure sodium lamp with an irradiation intensity of $\left.450 \mu \mathrm{mol} \cdot \mathrm{m}^{-2} \cdot \mathrm{s}^{-1}\right)$. The humidity of the soil was maintained at $65 \%$ of soil water capacity (SWC), with watering of the pots each day to maintain a constant weight $(5500 \mathrm{~g})$. Under these conditions, the plants were grown to the stage of the full development of the 2nd leaf. Next, one third of the plants were kept under this optimal watering (C); while the other plants had water withheld until the SWC reached $35 \%$ in the second third of pots, and $30 \%$ in the last third (5 and 6 days, respectively) under the same growth conditions. For the next 10 
days (9 days for D2) the plants were watering at these SWS levels to reach plants grown at the three levels of SWS: C (65\%), D1 (35\%), and D2 (30\%). Next, the youngest but fully-developed leaf was sampled for water-related parameters and for content of dehydrins; and the crowns for 2D-DIGE analysis. At least three biological and technical replicates of the leaves and crowns were harvested for these analyses. Samples were taken during the fourth hour of the light period. Samples for dehydrin content and 2D-DIGE analysis were immediately frozen in liquid nitrogen and kept at $-80^{\circ} \mathrm{C}$.

\section{Water Saturation Deficit (WSD)}

Immediately after sampling the leaves were cut into $1 \mathrm{~cm}$ long segments. After measurement of their weight (initial weight; Wi) on an analytical scale, the segments were fully water saturated in polyurethane cells for $3 \mathrm{~h}$ and weighed (weight after saturation; Ws). Afterwards, the segments were dried overnight at $95^{\circ} \mathrm{C}$ and the dry weight (DW) was measured. WSD (\%) was calculated as $\mathrm{WSD}=100 \times(\mathrm{Ws}-\mathrm{Wi}) /(\mathrm{Ws}-\mathrm{DW})$.

\section{Osmotic Potential (OP)}

The leaves were inserted into a sterile syringe and isolated by Parafilm PM-992 (Bemis). Syringes were kept at $-80^{\circ} \mathrm{C}$ in a freezer. Afterwards, the sample was defrosted at room temperature before the measurement of OP. The liquid needed for OP measurement on a HR 33T Dew Point Micrometer (Wescor) was obtained by pressure on the leaves in the syringe.

\section{Carbon Isotope ${ }^{13} \mathrm{C}$ discrimination}

Leaves for isotope analysis were dried $\left(80^{\circ} \mathrm{C}\right.$ until of constant weight), ground in a Micro ball mill MM 301 (Retsch). Discrimination of ${ }^{13} \mathrm{C}$ was measured by an IsoPrime High Performance Stable Isotope Ratio Mass Spectrometer (GV Instruments), connected with an Euro EA 3200 analyser (Eurovector), according to the manufacturer's instructions.

\section{Accumulation of Dehydrins}

Dehydrin accumulation was investigated by immunoblotting of protein soluble upon boiling with anti-dehydrin antibody (Enzo Life Sciences) described by Vítámvás et al. (2010). In short, proteins soluble upon boiling were extracted by Tris buffer [0.1 M Tris-HCl, $\mathrm{pH} 8.8$, containing complete EDTA-free protease inhibitor cocktail (Roche)], from frozen leaves ground in a mortar and pestle under liquid nitrogen. After the boiling step $(15 \mathrm{~min})$, the proteins were precipitated under acetone with $1 \%$ $ß$-mercaptoethanol. The protein concentrations were determined utilizing a 2-D Quant kit (GE-Healthcare). About $2.2 \mu \mathrm{g}$ of the extracted proteins were loaded into each well of $10 \%$ SDSPAGE (Laemmli, 1970). The proteins were electrophoretically transferred to nitrocellulose $(0.45 \mu \mathrm{m}$; Pharmacia Biotech). The anti-dehydrin antibody, bound to the protein bands, was visualized by BCIP/NBT staining (Bio-Rad). A GS-800 calibrated densitometer (Bio-Rad) was used for image capture of the visualized dehydrin bands. Densitometric quantification of the dehydrin bands was done by Quantity One version 4.6.2 software (Bio-Rad).

\section{D-DIGE Analysis}

Protein extraction from the frozen crowns was carried out as described by Wang et al. (2006) with some modifications. Briefly, $200 \mathrm{mg}$ of crowns (i.e., 9-12 plants) were ground in liquid nitrogen to a fine powder in $1 \mathrm{~mL}$ cold TCA in acetone with $0.07 \%$ DTT. After $30 \mathrm{~min}$ of incubation in a freezer $\left(-20^{\circ} \mathrm{C}\right)$, the homogenate was centrifuged $\left(10,000 \times\right.$ g; $\left.5 \mathrm{~min} ; 4^{\circ} \mathrm{C}\right)$; next, the supernatant was decanted and the pellet was washed twice $\left(10,000 \times \mathrm{g} ; 3 \mathrm{~min} ; 4^{\circ} \mathrm{C}\right)$. After overnight drying of the pellet at room temperature, the pellet was re-suspended in $0.7 \mathrm{~mL}$ phenol (Tris-buffered, $\mathrm{pH} 8.0$ ) and $0.7 \mathrm{~mL}$ SDS buffer (30\% sucrose, 2\% SDS, 0.1 M Tris- $\mathrm{HCl}, \mathrm{pH} 8.0,5 \%$ 2-mercaptoethanol), and then thoroughly vortexed and centrifuged (10,000 $\times$ g; $3 \mathrm{~min})$. The upper phenol phase was added to cold methanol with $0.1 \mathrm{M}$ ammonium acetate $\left(1: 5\right.$ volume ratio), kept $30 \mathrm{~min}$ at $-20^{\circ} \mathrm{C}$, and then centrifuged $\left(10,000 \times \mathrm{g} ; 5 \mathrm{~min} ; 4^{\circ} \mathrm{C}\right)$. The supernatant was discarded. The pellet was washed twice with cold methanol with $0.1 \mathrm{M}$ ammonium acetate, and twice washed with $80 \%$ acetone $\left(10,000 \times \mathrm{g} ; 3 \mathrm{~min} ; 4^{\circ} \mathrm{C}\right)$. The pellet was dried and dissolved in lysis buffer (30 mM Tris $\mathrm{pH} 8.0,7 \mathrm{M}$ urea, $2 \mathrm{M}$ thiourea, $4 \% \mathrm{w} / \mathrm{v}$ CHAPS). The $\mathrm{pH}$ of the lysate was adjusted to 8.5 by the careful addition of $50 \mathrm{mM} \mathrm{NaOH}$, and the protein concentration was quantified by use of a 2-D Quant kit (GE Healthcare). Protein extracts were labeled (with dye switching between repetitions) prior to electrophoresis with the CyDyes ${ }^{\mathrm{TM}}$ (GE Healthcare) according to the manufacturer's instructions. Ninety micrograms of the proteins $(30 \mu \mathrm{g}$ of each sample plus $30 \mu \mathrm{g}$ of internal standard) were loaded on each gel and separated by 2-DE (O'Farrell, 1975). Isoelectric focusing was run on ReadyStrip ${ }^{\mathrm{TM}}$ IPG strips ( $\mathrm{pH} 4-7,24 \mathrm{~cm}$; Bio-Rad) on a PROTEAN IEF cell (Bio-Rad) according to the manufacturer's instructions until $90,000 \mathrm{~V} h$ were reached. The rehydration buffer contained $9.8 \mathrm{M}$ urea and 4\% CHAPS. After equilibration of IPG strips in equilibration buffer with DTT, and then with iodoacetamide, the focused proteins were separated in the second dimension by 12.5\% SDS-PAGE (Laemmli, 1970). SDS-PAGE was performed in Ettan DALT six (GE Healthcare). Image capture of the gels was done using the PharosFX Plus (Bio-Rad) at a resolution of $100 \mu \mathrm{m}$.

Densitometric analysis of the scanned images was carried out using PDQuest Advanced 8.0.1 (Bio-Rad). Protein spot normalization was carried out using the local regression model, and the spot manual editing was carried out using the group consensus tool. The differentially abundant protein spots (at least a two-fold change; $p=0.05$ ) were chosen for spot excision (ExQuest Spot Cutter; Bio-Rad), and identification from preparative gels (2-DE of $750 \mu \mathrm{g}$ of internal standard sample) were stained by Bio-Safe Coomassie G-250 stain (Bio-Rad).

Protein identification was carried out by MALDI-TOF/TOF. After washing and desalting in ammonium bicarbonate $50 \mathrm{mM} / 50 \%$ methanol v/v, followed by $75 \% \mathrm{ACN} \mathrm{v/v}$, the spots were then digested in situ with Trypsin Gold (mass spectrometry grade, Promega, $10 \mathrm{mg} / \mathrm{mL}$ in $20 \mathrm{mM}$ ammonium bicarbonate) using an Ettan Digester robot (GE Healthcare) from the same workstation. Automated spotting of the samples was carried out with the spotter of the Ettan Spot Handling Workstation (GE Healthcare). Peptides dissolved in a 50\% ACN containing 
0.5\% TFA $(0.7 \mathrm{~mL})$ were spotted on MALDI-TOF disposable target plates (Applied Biosystems) before the deposit of $0.7 \mathrm{~mL}$ of CHCA $(10 \mathrm{mg} / \mathrm{mL}$ ACN $50 \% \mathrm{v} / \mathrm{v} / \mathrm{TFA} \quad 0.1 \% \mathrm{v} / \mathrm{v}$, Sigma Aldrich). Peptide mass determinations were carried out using an Applied Biosystems 5800 Proteomics Analyzer (Applied Biosystems). Both the peptide mass fingerprinting and tandem mass spectrometry (MS/MS) analyses in reflection mode were carried out with the samples. Calibrations were carried out with the peptide mass calibration kit for 4700 (Applied Biosystems). Proteins were identified by searching against the SWISSPROT, TREMBL, NCBI, and a wheat expressed sequence tag database generated from the databases using MASCOT [Matrix Science, http://www.matrixscience.com; NCBInr downloaded on June 6, 2014 (40,910,947 sequences; 14,639,572,021 residues); EST_monocots downloaded on December 16, 2013 (45,575,892 sequences; 7,829,773,678 residues)]. All searches were carried out using a mass window of $100 \mathrm{ppm}$ and a fragment mass window tolerance of $0.5 \mathrm{Da}$, and with "Viridiplantae (Green Plants)" as taxonomy for the NCBI database (1,717,798 sequences). The search parameters allowed for the carboxyamidomethylation of cysteine, dioxidation of tryptophan, and oxidation of methionine. Homology identification was retained with the probability set at $95 \%$. All identifications were manually validated. Protein spots containing more than one significantly identified protein were excluded from further analysis. In the case of protein sequences identified as "predicted protein" with an unknown function, protein BLAST search (BLASTP) was carried out against the NCBInr database [NCBInr 20150217 (61,023,628 sequences) and UNIPROT database (UniProtKB Protein) generated for BLAST on Feb 2, 2015 (91,447,086 sequences)] to find an identified protein revealing a significant sequence similarity. Theoretical pI and MW values were calculated from the identified sequence in NCBInr using ExPASy tool (www.expasy.org). The protein functions were assigned using a protein function databases Inter-Pro (http://www.ebi.ac.uk/interpro/), Pfam (http://pfam. janelia.org/) and Gene Ontology (http://www.geneontology. $\operatorname{org} /)$.

\section{Statistical Analyses}

For each treatment, the statistical analysis was carried out with at least three biological replicates for proteomics, three biological and three technical replicates for WSD, OP, discrimination of ${ }^{13} \mathrm{C}$, and dehydrin accumulation analysis. By analyzing protein abundance values, only statistically significant results were considered (One-Way and Two-Way analysis of variance (ANOVA), $p<0.05$ ), and differentially abundant proteins with a ratio of at least 2.0 in absolute value, observed in at least one condition, were selected. A principal component analysis (PCA) was run on the protein spots matched on the different spot maps for qualitative appreciation of the proteomic results. Two-Way ANOVA and PCA were performed on Statistica version 10 software (StatSoft). For detailed analysis of proteome changes, the protein ratio was calculated between treatments and statistically analyzed by Student's $T$-test $(p<0.05)$. All spot densitometric data from samples grown under D1 and D2 were also used as one data set to obtain common plant responses to the drought condition (D). Cluster analysis of the protein spot relative abundance of selected protein spots has been carried out using PermutMatrix software (version 1.9.3; Caraux and Pinloche, 2005). For cluster analysis, Z-score transformation of spot density data was carried out. Euclidean distances and Ward's minimum criteria were used for the analysis.

\section{Results}

\section{Physiological Characterization of Barley Plants}

In barley leaves, the following physiological characteristics were determined at each sampling (in each experimental variant): water saturation deficit (WSD), osmotic potential (OP), ${ }^{13} \mathrm{C}$ discrimination $\left(\Delta^{13} \mathrm{C}\right.$; Figure 1). Drought led to an increase in WSD and a decrease in OP, with D2 leading to higher dehydration than D1 (milder drought). Regarding dehydrin DHN5 relative accumulation and $\Delta^{13} \mathrm{C}$, there was a significant increase in DHN5 and a significant decrease in $\Delta^{13} \mathrm{C}$ upon drought with respect to the control; however, there were no significant differences between the two drought treatments. Plants grown under drought conditions revealed slower growth and development than plants under optimal watering (C) conditions.

\section{Proteomic Analysis}

Total proteome analysis of barley crowns using the 2D-DIGE approach has led to detection of 1004 distinct protein spots thorough all gels in experiments (matched and normalized) in the pI range 4-7 (Figure 2, details in Supplementary Data). Quantitative analysis of protein spot density (protein spot relative accumulation) has led to detection of 105 protein spots (spots of interest), revealing significant quantitative differences between the treatments (more than two-fold change at 0.05 level); the spots were selected for MALDI-TOF/TOF protein identification. Eighty-two spots of interest were successfully identified. However, 6 spots $(118,1104,4007,6402,7702$, and 8001) showed double identification in the same spots; therefore they were excluded from quantitative analyses. Cluster analysis of the spots of interest revealed eight different patterns of quantitative changes between the three treatments (Figure 3). Principal component analysis (PCA) of all the matched protein spots revealed a clear distinction between the three treatments $(C$, D1, D2), with a prominent difference between the $\mathrm{C}$ and drought treatments (Figure 4A). Protein spots of interest are placed in the distant parts of the PCA protein spot area of protein relative accumulation (Figure 4B). The sum of standard deviations of density of the protein spots under C, D1, and D2 conditions showed different variabilities in the spot density of spots of interest $(0.19,0.17,0.24$, respectively), and in the density of all matched and normalized spots $(2.06,0.68,1.05$, respectively).

Cluster analysis revealed the presence of 8 clusters based on the differential pattern of protein abundance with respect to the individual treatments (C, D1, D2). Cluster 1 includes proteins with the highest abundance at D1 with respect to the $\mathrm{C}$ and D2 treatments; clusters 2 and 3 encompass proteins revealing an increase under drought with respect to the C; cluster 4 includes proteins revealing an enhanced abundance at D2 with respect to $\mathrm{D} 1$ and the $\mathrm{C}$; cluster 5 encompasses proteins revealing a 


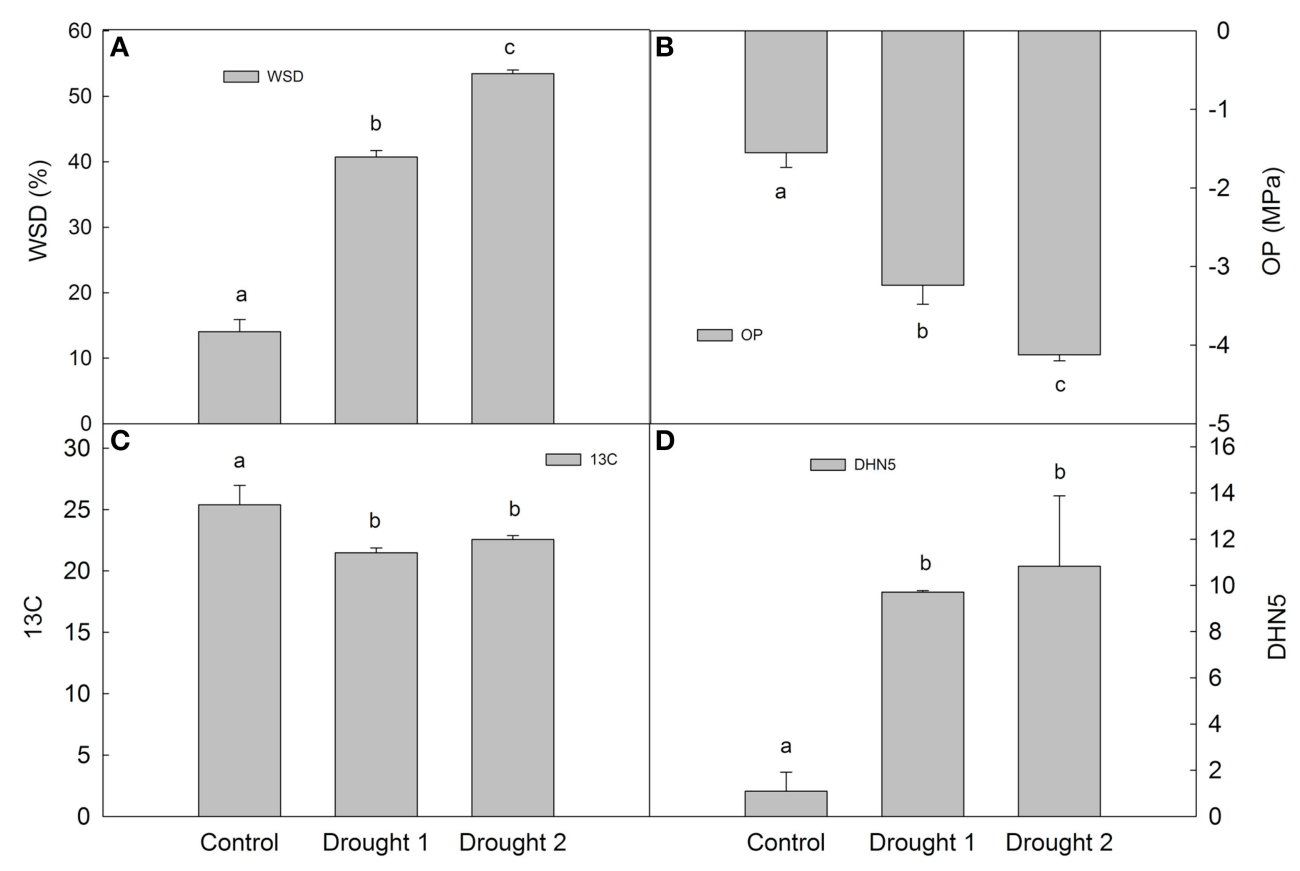

FIGURE 1 | Water saturation deficit (WSD; A), osmotic potential (OP; B), ${ }^{13} \mathrm{C}$ discrimination (13C; C) and dehydrin 5 (DHN5) relative accumulation (D) in Amulet plants sampled under control, drought 1 and drought 2 conditions. Error bars indicate standard deviation (SD), different letters indicate significant differences at 0.05 level using Duncan's multiple range test. decreased abundance at D1 with respect to D2 and C conditions; cluster 6 includes proteins revealing a decrease under both drought treatments with respect to the C; and clusters 7 and 8 encompass proteins revealing a decrease at D2 with respect to D1 and $\mathrm{C}$ conditions. A Venn diagram shows that: 8 proteins reveal an increase, and 14 proteins reveal a decrease, specifically in ratio $\mathrm{D} 1 / \mathrm{C}$; further, that 24 proteins reveal an increase, and 19 proteins reveal a decrease, specifically in ratio D2/C; while 15 proteins and 13 proteins are increased and decreased, respectively, under both drought treatments with respect to the $\mathrm{C}$ (Figure 5).

Significant differences between D2 and D1 in 27 spots of interest were also found (Table 1, details in Supplementary Data). An increase in accumulation was shown in 15 spots of interest ( 9 were identified). A decrease in accumulation was revealed in 12 spots of interest ( 9 were identified). Four protein spots (4614-UDP-glucose 6-dehydrogenase, 7006glutathione peroxidase, and non-identified spots 7001 and 8104) revealed a continuous significant increase between $C$, D1, and D2 treatments (in all ratios). No continuous significant decrease was observed in the data set obtained. Seventy-six distinct protein spots were identified as 68 distinct proteins, distributed in 15 major functional categories regarding biological processes (Figure 6, Table 1) including: signaling and regulatory proteins (6 spots), proteins involved in regulation of DNA and RNA activity and processing (9 spots), cytoskeleton and transport proteins (3 spots), proteins involved in energy metabolism including carbohydrate metabolism ( 9 spots), ATP metabolism (4 spots), respiration (5 spots), and photosynthesis (2 spots), proteins involved in amino acid metabolism (10 spots), protein metabolism (8 spots), S-adenosylmethionine (SAM) metabolism (1 spot), flavonoid metabolism (3 spots), phospholipid metabolism (1 spot), phytohormone metabolism (1 spot), stress and defense responses (14 spots). Four proteins were identified in multiple proteins spots (putative $32.7 \mathrm{kDa}$ jasmonate-induced protein-4201, 5202; UDP-glucose 6-dehydrogenase-4611, 4614; 2,3-bisphosphoglycerateindependent phosphoglycerate mutase-like-4708, 5701; methionine synthase-2813, 7802, 8806, 8808, 8809, 9801). A complete GO annotation (Gene Ontology database) regarding the three GO criteria (cellular localization, molecular function, and biological process) of the identified protein spots and detailed MS/MS analysis is provided in the Supplementary Data.

\section{Discussion}

\section{The Effect of Drought Compared to Control}

Two different drought intensities (35 and 30\% of SWC; D1 and D2, respectively) were studied in the experiment. Drought induces profound alterations in plant metabolism directed toward an adjustment of plant cells to dehydration. Determination of physiological parameters WSD, OP, and $\Delta^{13} \mathrm{C}$ revealed significant dehydration and limited stomatal openness (limited $\mathrm{CO}_{2}$ availability) in drought-treated barley plants vs. controls. Similarly, an enhanced accumulation of dehydrin protein DHN5 on the immunoblots indicates cellular dehydration. Interestingly, standard deviation in the 


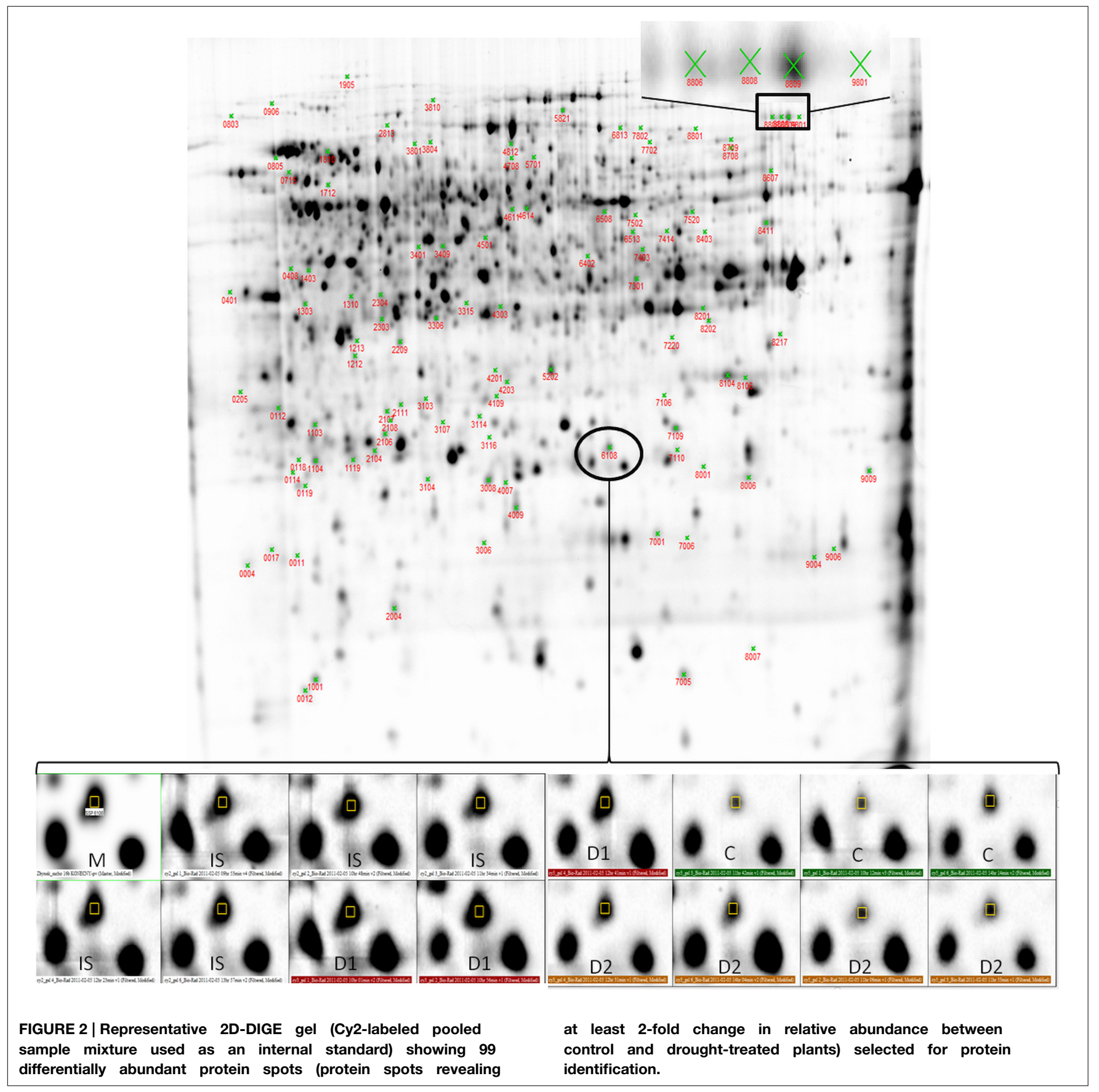

physiological parameters and spot density indicated some trends in the samples. The least difference in variability of the data found in D1 samples could indicate a functional stress response of plants (slower growth and development, accumulation of stress, and defense proteins and metabolites). The higher variability in the control condition could be the result of faster growth and development of plants under optimal watering, while the population of individual plants could be slightly differentiated in the same biological repetition. The higher variability in D2 could be related to more severe water condition of the plants, where the damage could influence the physiological and quantitative proteomics data. What could happen with the sample if in some part of the plant a higher ratio of a senescence process or cell death occurred? For example, density analysis of spot 7109 (GST6, cluster 2; Supplementary Data) revealed that after a high increase in D1, the accumulation was decreased in D2. However, in a detailed view, half of the D2 samples accumulated at similar levels as in D1; and in the other half at a similar level as in the C. Therefore, the variability in the data set could represent an additional explanation of plant status (stress response and plant damage) and the obtained proteome results, which are discussed in the following parts of the text. 


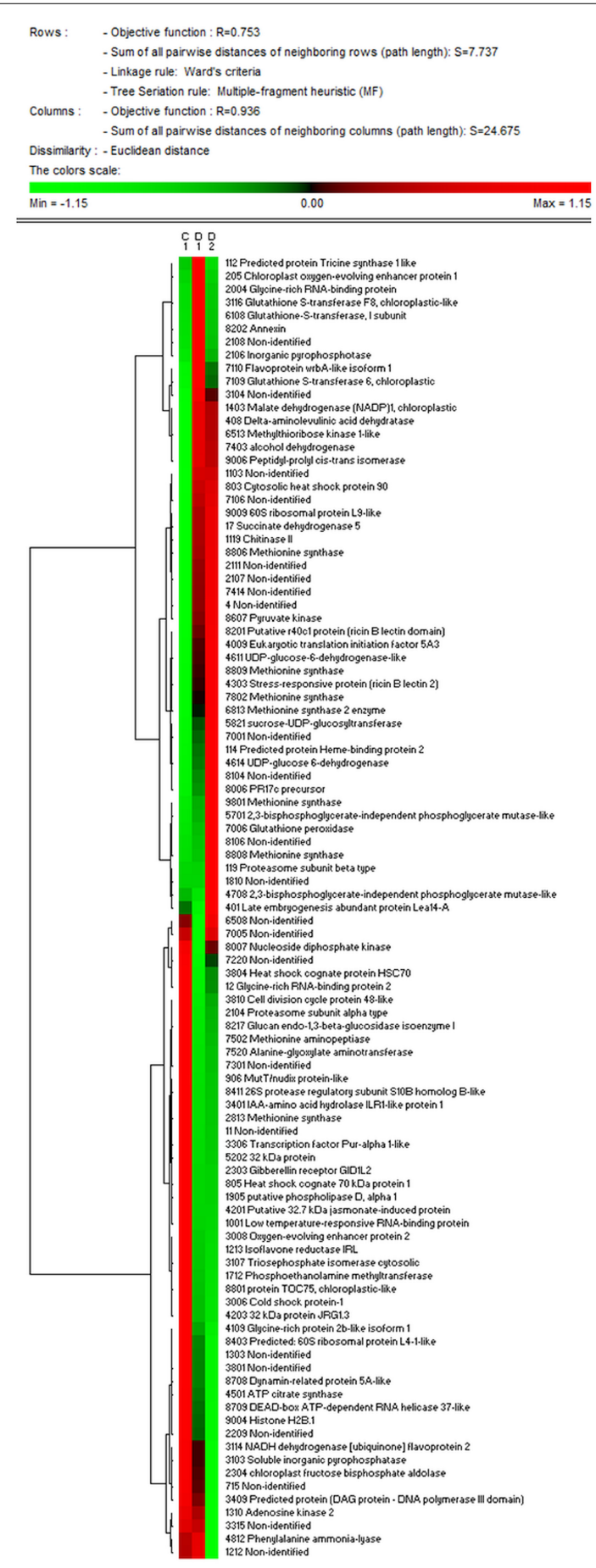

FIGURE 3 | Results of cluster analysis of 99 protein spots selected for protein identification. Cluster analysis shows patterns of protein spot relative abundance in samples grown under control (C), drought 1 (D1) and drought 2 (D2) conditions. Euclidean distance and Ward's minimum criteria were applied for the analysis.

The qualitative analysis of proteome not only significantly distinguished spots between control and drought conditions, but also differences ( 27 spots) between both drought treatments were found. Some spots identified as one protein (e.g., 5 spots of methionine synthase in clusters 3,4 , and 6) revealed different abundance between treatments and thereby were placed to different clusters. This could indicate different functionality of the isoforms and/or post-translational modifications under varying drought conditions and demonstrates one of the main advantages of the gel-based method compared to the gel-free approach. For example, the isoform analysis was shown by Erban and Hubert (2015) for zymogens and active-enzyme forms of house dust mite fecal allergens.

In comparison to previous proteome studies on barley's response to drought treatment, in this study, more proteins were found and identified (even for more robust protein accumulation between treatments $=$ two-fold change). Wendelboe-Nelson and Morris (2012) identified 24 leaf and 45 root differentially accumulated proteins (however, the roots were cultivated under different conditions than the leaves) between the drought sensitive European malting barley Golden Promise (GP), and the Iraqi Basrah barley adapted to hot and dry conditions. Only four proteins from the leaf tissue (HSP70, OEE1 and 2, and methionine synthase) were the same as in our study. GP showed a lower expression and/or accumulation of constitutively present proteins, which could be connected to the slower response of GP to stress, compared to Basrah. According to the results of Wendelboe-Nelson and Morris (2012), our cv. Amulet showed a similar accumulation pattern as a sensitive GP. However, the authors did not show any detailed information about soil water content between genotypes (e.g., caused by different rates of transpiration), and did not carefully take into account their possible different response in biomass allocations (and thus their real drought adaptability). Ashoub et al. (2013) found about 22 accumulated and 6 down-accumulated proteins between tolerant $(\# 15,141)$ and sensitive $(\# 15,163)$ cultivars. After 5 days, pot soil field capacity drops to $10 \%$; this evokes very sandy soil, quick, and deep stress with reduced genotype-based acclimation ability. Compared to Ashoub et al. (2013), only 3 proteins (methionine synthase, HSP90, and HSP70) were identified also in our study. Ghabooli et al. (2013) found 62 protein spots (only 45 was identified) with significant differences between Piriformospora indica-colonized GP plants compared with non-inoculated plants in response to drought stress (14 days; 25\% field capacity). Compared to our study, only OEE1, peptidyl-prolyl cis-trans isomerase, and $60 \mathrm{~S}$ ribosomal protein were found in Ghabooli et al. (2013). Kausar et al. (2013) identified 24 protein spots extracted from shoots in drought-sensitive Pakistani genotype 004186 and 19 spots in drought-tolerant Pakistani genotype 004223 after only 3 days of treatment. The identifications shared with our study included only protein spots identified as malate dehydrogenase, HSP70, OEE1, OEE2, methionine synthase, and glutathione transferase (GST). We found an analogous protein accumulation to patterns found in sensitive genotypes in all studies mentioned above (for details, see the text below).

In the paragraphs below, the proteins identified are briefly discussed with respect to their biological functions:

Proteins involved in signaling and regulatory processes, phospholipid metabolism: 
A

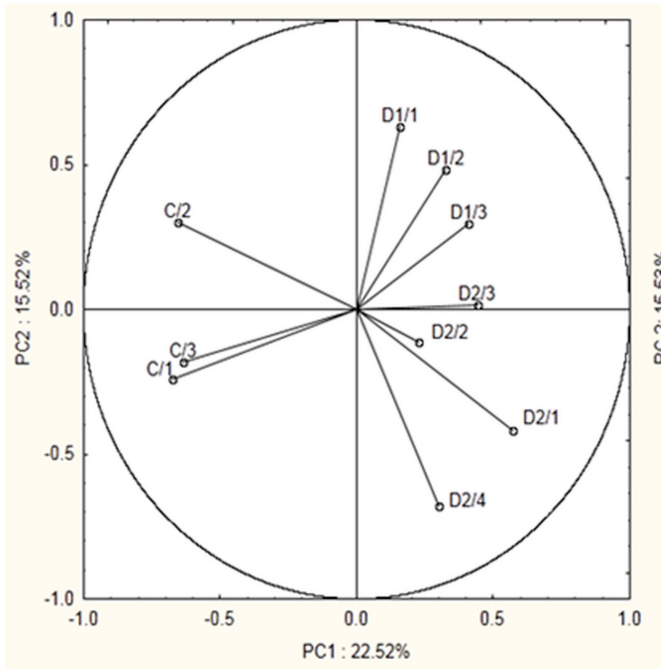

FIGURE 4 | Results of PCA analysis showing a position of 99 protein spots revealing significant differences between experiment variants and selected for protein identification. (A) Position of the individual samples (control-C1-C3; drought
B

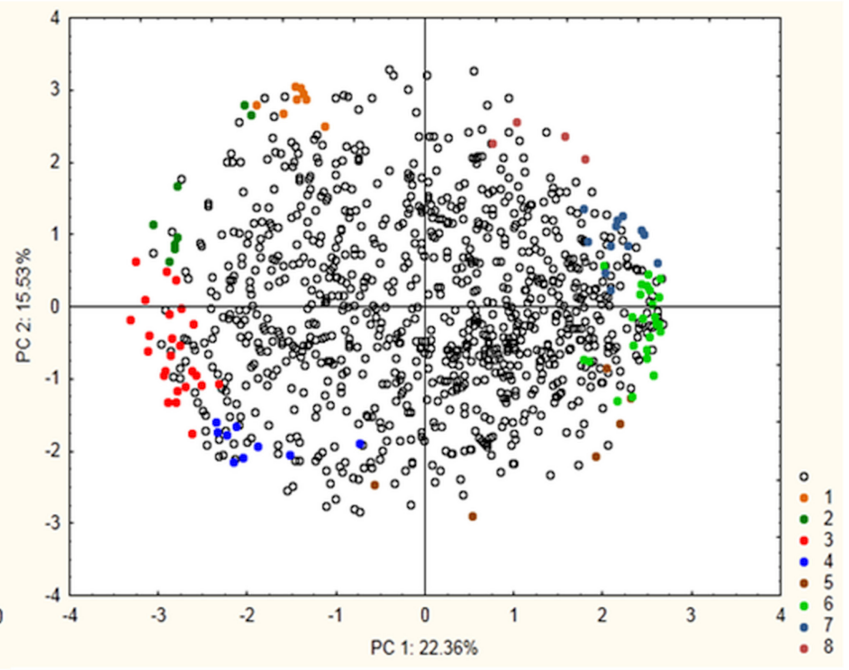

1-D1/1-D1/3; drought 2-D2/1-D2/4) are indicated. (B) Position of the individual protein spots are indicated. Colored spots 1-8 indicate 99 selected protein spots with their indicated cluster positions according to cluster analysis.

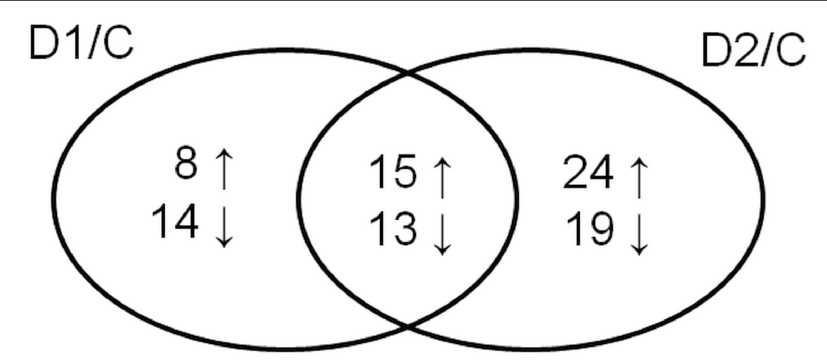

FIGURE 5 | Venn diagram showing protein spots revealing a significant increase $(\uparrow)$ or a decrease $(\downarrow)$ in drought-treated samples with respect to control ones (D1/C; D2/C).

The accumulations of all of proteins in this functional group decreased under drought conditions, and belong in cluster 6 . Generally, the decrease could be explained by a reduction of plant growth and development under drought conditions.

Putative phospholipase D, alpha 1 (ssp 1905) catalyzes the cleavage of phospholipids, leading to formation of phosphatidic acid (PA) and other small molecules that can act as signals.

Proteins (ssp 4201, 4203, and 5202) were identified as jasmonate-regulated lectins. Several lectins have been reported to accumulate in cereal crown tissues, where the shoot apex is located, and to affect shoot apex development. For example, an accumulation of lectin VER2 was reported in cold-treated wheat crown tissue until vernalization (Rinalducci et al., 2011; Kosová et al., 2013). Therefore, in our study, the observed results (i.e., a decrease under drought) in these proteins indicated that the proteins belong into the several lectins with some stimulating role in plant development contrary to VER2 lectin in plants under cold treatment found in Rinalducci et al. (2011) and Kosová et al. (2013).

Gibberellin receptor GID1L2 (ssp 2303) is a part of the gibberellins (GAs) perception process (Ueguchi-Tanaka et al., 2007). A decrease in ssp 2303 relative abundance under both drought treatments, with respect to the control, corresponds well with the adverse effects of stress on plant growth and development.

Protein cdc48 (ssp3810) is involved in the cell division process, and is known to be downregulated in differentiated cell types. Up to now, no evidence of such protein identification was found in studies on plant abiotic stress response. However, Skadsen et al. (2000) found also decrease of cdc48 mRNA after inoculation of barley spikes with Fusarium graminearum.

Proteins involved in DNA and RNA regulatory processes:

Generally, the proteins involved in DNA and RNA regulatory processes have a role in plant development or growth and are decreased under drought.

MutT/nudix protein (ssp 906; cluster 6) belongs to the family of nucleoside diphosphate hydrolases, which are involved in the repair of DNA during replication. A revealed decrease in accumulation could indicate a reduced speed of replication (i.e., slower plant growth and development).

Histone H2B.1 (ssp 9004; cluster 7) belongs within the histone group. Several nucleosomal histones (histone H2A.1, histone H2B.10, histone H3.2) were found to be altered (increased or decreased) in germinating durum wheat seedlings upon salt stress (Fercha et al., 2013).

Changes in glycine-rich RNA binding proteins (ssp 12, cluster 5 ; 2004, cluster 1) were reported also in wheat upon cold (Rinalducci et al., 2011; Kosová et al., 2013). The members of the glycine-rich RNA-binding protein family are known to 


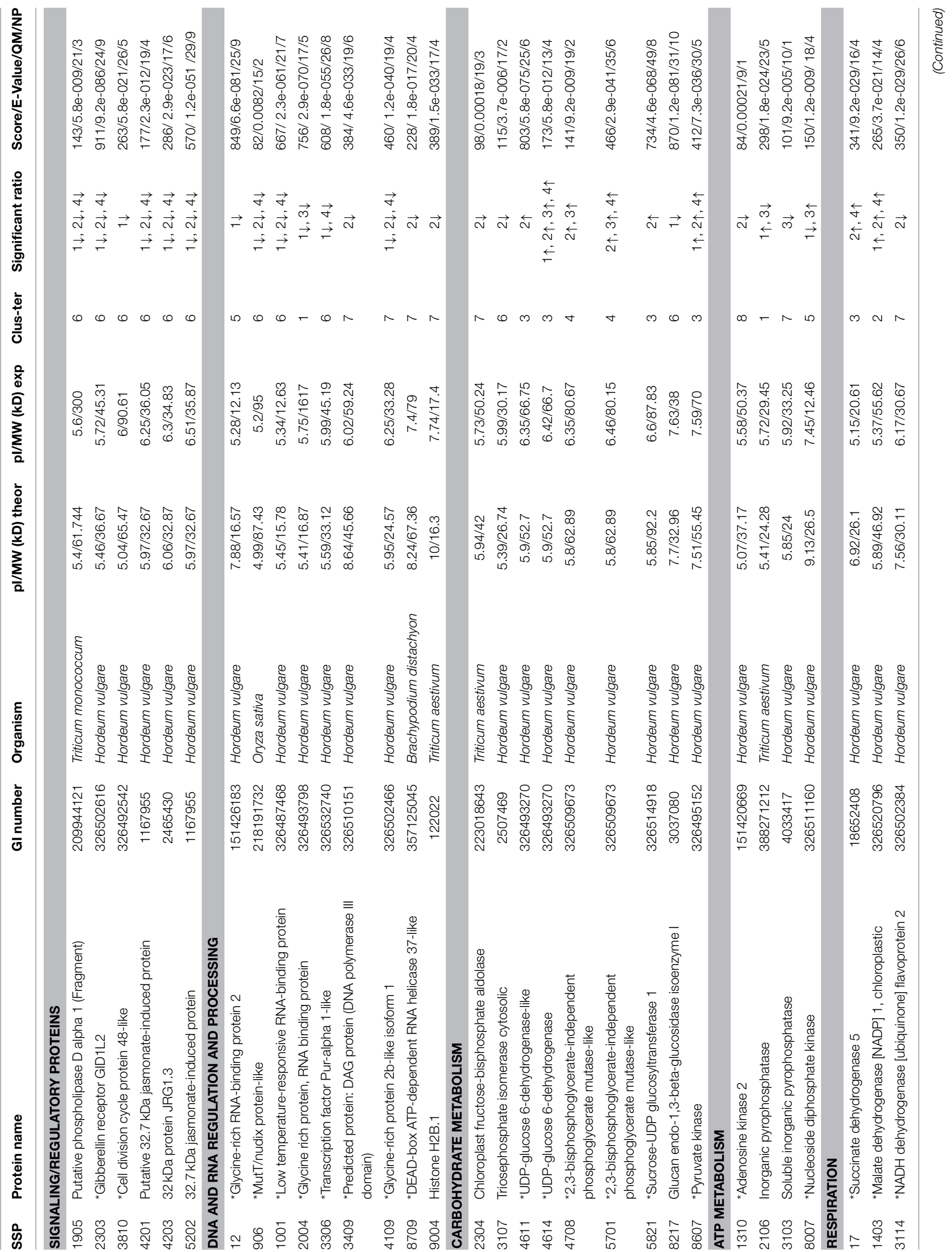




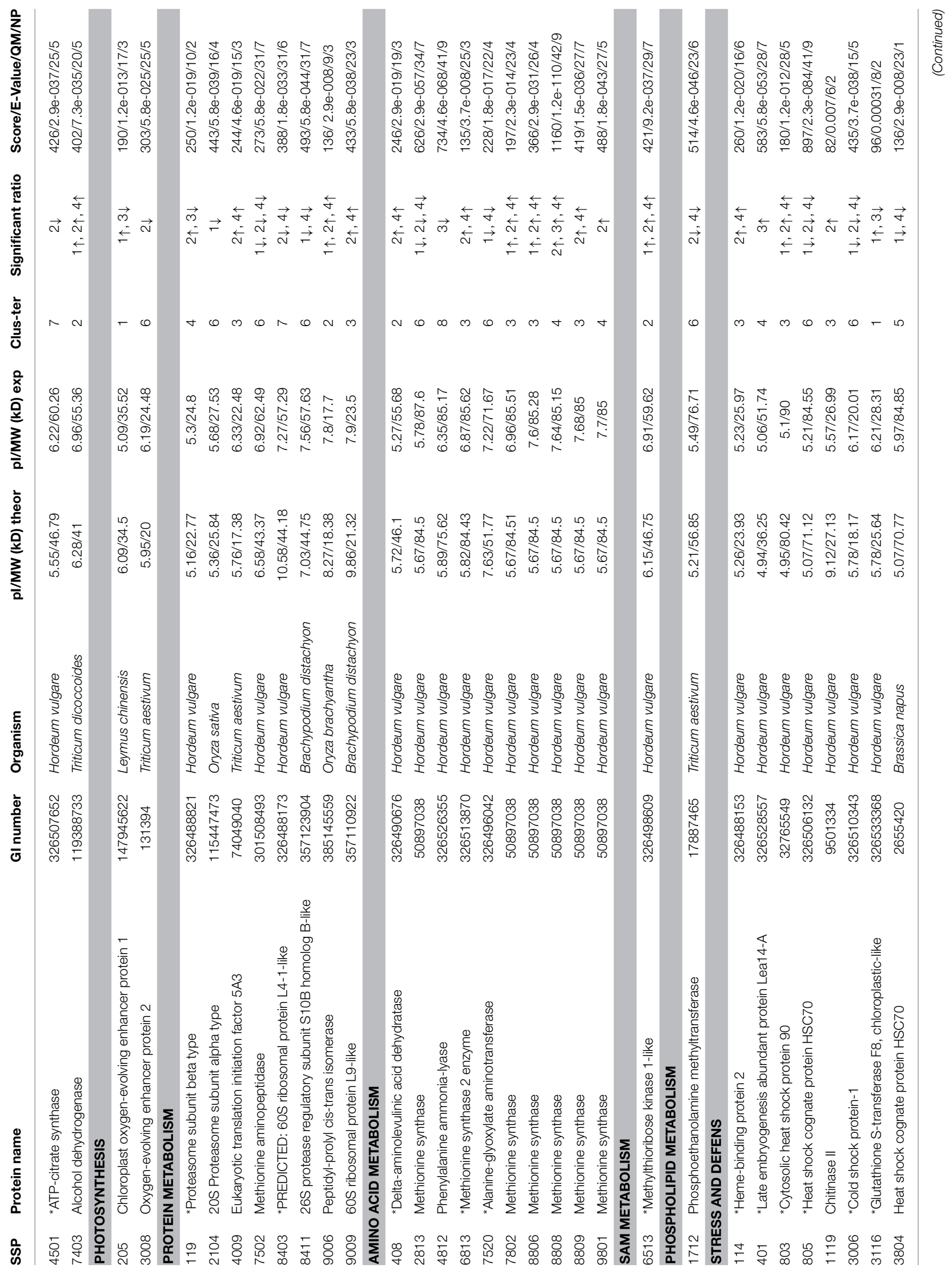




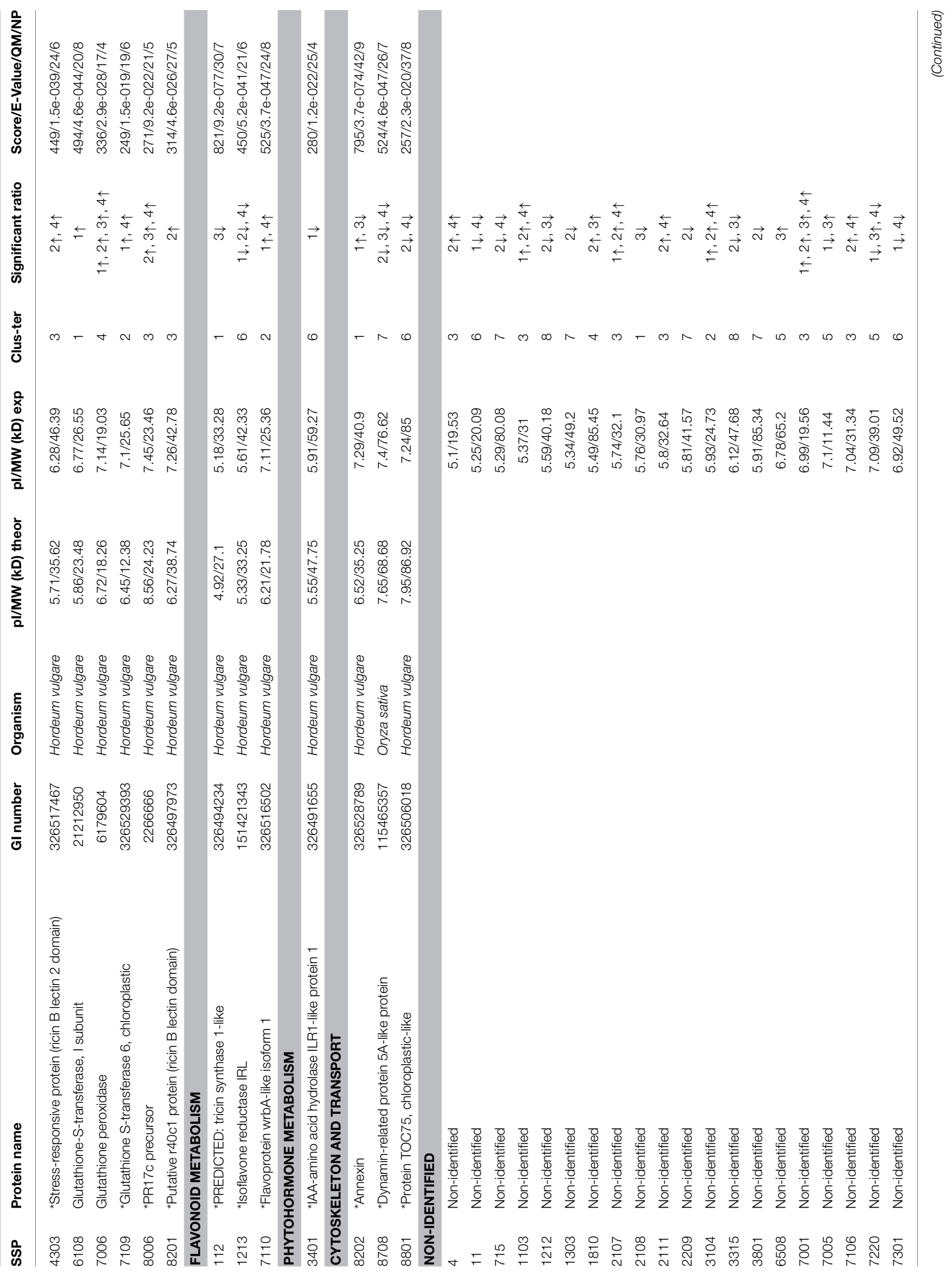




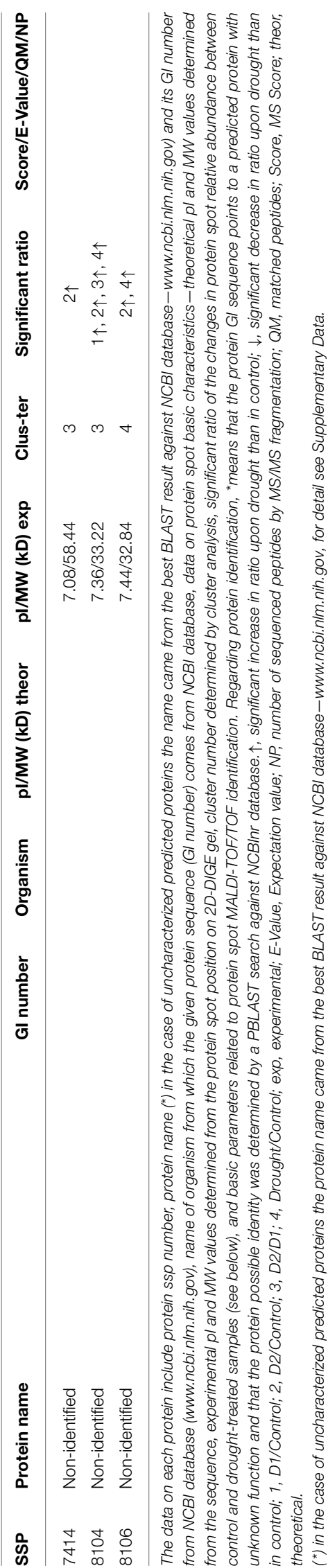

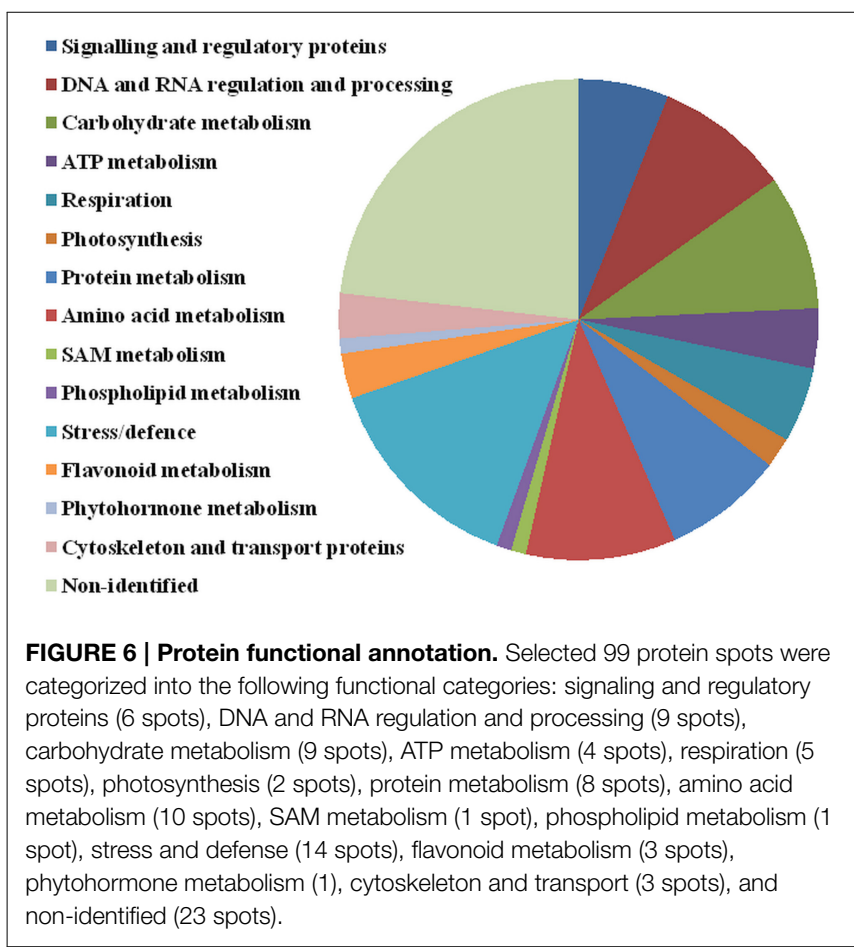

regulate RNA processing, transport, and to reveal regulatory functions.

Transcription factor Pur-alpha-1 (ssp 3306, cluster 6) is involved in the initiation of nuclear DNA replication. Its decrease during drought may indicate a reduced rate of cell division upon stress conditions. It is in according with a decrease in protein containing DNA polymerase III domain (ssp 3409, cluster 7) accumulation. DNA polymerase III is a prokaryotic DNA polymerase involved in the replication of circular DNA; its homologs are found in plants in mitochondria and plastids (mitochondrial and plastidic DNA polymerases).

DEAD-box ATP-dependent RNA helicase (ssp 8709, cluster 7) was described to regulate mRNA export from nucleus to cytoplasm (i.e., to function as a RNA chaperone). In Arabidopsis thaliana, a mutation in the locus encoding DEAD-box RNA helicase has led to enhanced cold induction of CBF2 and its downstream genes including Cor/Lea genes (Gong et al., 2005). According to Wendelboe-Nelson and Morris (2012), who found increase of DEAD box RNA helicase in droughtstressed roots of drought-tolerant Basrah compared to no change in sensitive genotype GP. Taken together, a higher trend in dehydrin accumulation and revealed decrease of this protein is also supporting our idea about Amulet as a sensitive genotype.

\section{Energy Metabolism - ATP Metabolism, Carbohydrate Metabolism, Photosynthesis, Respiration}

Stress factors profoundly affect energy metabolism, since plant adjustment to an altered environment generally means an enhanced need for immediately available energy. Changes in several enzymes involved in ATP metabolism, especially the 
cleavage of phosphate bonds, were found in our study (adenosine kinase 2-ssp 1310, cluster 8; inorganic pyrophosphatase-ssp 2106, cluster 1, and ssp 3103, cluster 7; nucleoside diphosphate kinase-ssp 8007, cluster 5). An enhanced need for ATP as a universal energy source has been reported in many proteomic studies aimed at plant stress responses, as indicated by the reports on increases in ATP synthase subunits (Vítámvás et al., 2012; Kausar et al., 2013). The major sources of novel ATP molecules represent both processes of anaerobic and aerobic respiration as well as photosynthesis. The anaerobic portion of respiration includes glycolysis. An increased relative abundance of glycolytic enzymes was found in several proteomic studies on stress-treated plants (Vítámvás et al., 2012; Kosová et al., 2013). However, in the present study, a decrease in some glycolytic enzymes: cytosolic triosephosphate isomerase (ssp 3107, cluster 6), and chloroplast fructose bisphosphate aldolase ( $\operatorname{ssp} 2304$, cluster 7); and an increase in others: 2,3-bisphosphoglycerate-independent phosphoglycerate mutase-like (ssp 4708, 5701, cluster 4), and pyruvate kinase (ssp 8607, cluster 3 ) were found under drought, with respect to the controls. A possible explanation of the observed difference could lie in the fact that the samples for proteome analysis were taken from plants exposed to long-term drought treatment, and the plants were fully acclimated to altered conditions without need for extra energy.

Regarding anaerobic respiration, an increase in alcohol dehydrogenase (ssp 7403, cluster 2) was found under drought. Regarding aerobic respiration, a drought-induced decrease in Krebs cycle enzyme ATP-citrate synthase (ssp 4501, cluster 7) and in complex I of respiratory electron transport chain (NADH dehydrogenase [ubiquinone] flavoprotein 2-ssp 3114, cluster 7) was found. In contrast, the levels of other Krebs cycle enzymes-succinate dehydrogenase (ssp 17, cluster 3), and malate dehydrogenase (ssp 1403, cluster 2) were increased upon drought with respect to the controls. These data indicate stress-induced imbalances in aerobic metabolism (imbalances between primary electron transport reactions and secondary enzymatic reactions) and an enhanced risk of ROS formation, which results in the downregulation of aerobic electron transport reactions, and a relative upregulation of alternative anaerobic pathways. Similar results (increase in alcohol dehydrogenase, formate dehydrogenase, aldehyde dehydrogenase) were obtained by Fercha et al. (2014) in salt-treated germinating wheat seedlings indicating the severe impact of drought on the aerobic portion of energy metabolism in our study.

Photosynthesis is known to be very sensitive to several stresses including cold, drought, and salinity. In our study, changes in two components of the oxygen-evolving complex (OEC) were found: proteins OEE1 (PsbO; ssp 205, cluster 1), and OEE2 (PsbP; ssp 3008, cluster 6). These dynamics indicated an increase under the milder drought (D1) with respect to the controls; however, a decrease under the more severe drought (D2). Changes in OEC proteins were found in drought-treated wheat genotypes (intolerant Kukri; tolerant Excalibur, and RAC875; Ford et al., 2011). Changes in OEE1 and OEE2 proteins were frequently found in salt-treated barley (Rasoulnia et al., 2011; Fatehi et al., 2012) and durum wheat (Caruso et al., 2008). Moreover, increase of OEC proteins were found in our previous studies on cold-acclimated wheat (Vítámvás et al., 2012) or barley (Hlaváčková et al., 2013). Additionally, an increase in OEE1 protein was observed in drought-treated barley infected by Piriformospora indica (Ghabooli et al., 2013). WendelboeNelson and Morris (2012) have demonstrated a decrease of OEE1 in stressed leaves of the sensitive barley GP, compared to the increase of OEE2 in tolerant Basrah. Kausar et al. (2013) showed an increase in OEE proteins under milder drought and in tolerant plant materials; while also showing a decrease under severe drought or in sensitive plant materials. These findings are in accordance with our findings, and we can postulate Amulet as a sensitive genotype to drought. However, the lack of other photosynthetic proteins corresponded with the material used (crowns are a non-photosynthetic tissue; see (Hlaváčková et al., 2013) for a comparison of crown and leaf proteome); therefore, only two photosynthetic proteins with a difference in protein accumulation were found.

Regarding carbohydrate anabolism, an increased relative abundance of UDP-glucose 6-dehydrogenase (ssp 4611, 4614, cluster 3), and sucrose-UDP-glucosyltransferase (ssp 5821, cluster 3) was found under drought. An increase in UDP-glucose 6-dehydrogenase may indicate enhanced synthesis of pectins and hemicelluloses, as well as the remodeling of cell walls in response to stress. Generally, in our previous studies on coldacclimated wheat and barley (Vítámvás et al., 2012; Hlaváčková et al., 2013), the decrease of accumulation of the sucroseUDP-glucosyltransferase and UDP-glucose 6-dehydrogenase was observed. It implicates specific plant response to different abiotic stresses.

\section{Protein Metabolism, Amino Acid Metabolism, SAM Metabolism}

The stress acclimation process is also associated with significant alterations in protein metabolism, regarding both protein biosynthesis and degradation. Alterations in protein biosynthesis are reflected in the changes of 60S ribosomal proteins L4-1-like (ssp 8403, cluster 7), L9-like (ssp 9009, cluster 3), as well as in eukaryotic translation initiation factor 5 A3 (ssp 4009, cluster 3 ). Alterations in ribosomal proteins are described in several studies that focused on stressed wheat and barley plants (Patterson et al., 2007; Vítámvás et al., 2012; Ghabooli et al., 2013; Fercha et al., 2014; Gharechahi et al., 2014), which indicated an enhanced need for novel proteins during stress acclimation. An increase in eukaryotic translation initiation factor eIF5A3 (ssp 4009) was found under drought with respect to the $\mathrm{C}$. It has been found that eIF5A not only functions as an initiation translation factor, but it can also undergo a post-translational modification of lysine residue to hypusine, and that the stoichiometry of different hypusinated forms of eIF5A can affect a switch between cell proliferation and cell death (Thompson et al., 2004). An increase in eIF5A2 in spring wheat Sandra under cold (with respect to the C), and a relatively enhanced level of eIF5A2 in spring wheat Sandra (with respect to winter wheat Samanta) was found by Kosová et al. (2013).

Protein conformation is regulated by peptidyl-prolyl cis-trans isomerase ( $\operatorname{spp} 9006$, cluster 2). Alterations in two isoforms of peptidyl-prolyl cis-trans isomerase were also found in barley 
cv. GP colonized by Piriformospora indica when subjected to drought (Ghabooli et al., 2013). An increased rate of protein degradation, associated with alterations in the metabolism of stressed plants, is indicated by a drought-increased level of the proteasome subunit beta type (ssp 119, cluster 4). However, some identified proteasome subunits proteins revealed a decrease in accumulation-i.e., $26 \mathrm{~S}$ protease regulatory subunit S10B homolog B-like (ssp 8411, cluster 6), and proteasome subunit alpha type (ssp 2104, cluster 6). Proteasomes are involved in the degradation of ubiquitin-tagged proteins. Alterations in proteasome subunits were found in several proteomic studies dealing with abiotic stresses (Rampitsch et al., 2006; Rinalducci et al., 2011; Fercha et al., 2013; Ghabooli et al., 2013).

Aminopeptidases catalyze protein degradation by the hydrolysis of $\mathrm{N}$-terminal amino acid. Methionine aminopeptidase (ssp 7502, cluster 6) was found to be decreased upon both drought treatments with respect to the control. However, leucine aminopeptidase RNAs, proteins, and activities have been found to be increased following drought and wound stress signal systems, such as methyl jasmonate and abscisic acid in tomato (Chao et al., 1999).

Significant alterations were also found in several enzymes involved in amino acid metabolism. It should be noted that amino acids not only form peptides and proteins, but they are also involved in the metabolism of carbon and nitrogen, as well as in the metabolism of several stress-related compounds (e.g., S-adenosylmethionine metabolism, metabolism of phenolic compounds).

Delta-aminolevulinic acid dehydratase (ssp 408) catalyzes the first and rate-limiting step of the conversion of non-protein amino acid delta-aminolevulinic acid to porphyrin molecules, namely chlorophyll. In our results, the cv. Amulet showed an increase of this protein in D2 and D, which is connected to the greater accumulation of Heme-binding protein (ssp 114), and an increase in glutathione S-transferase (ssp 3116, 6108, and 7109). An increase in delta-aminolevulinic acid causes porphyria (Vanhee et al., 2011). All 6 of the identified methionine synthases, except one, showed increased accumulation upon drought. Wendelboe-Nelson and Morris (2012) found an increase in stressed leaves of the tolerant Basrah genotype; while Ashoub et al. (2013) found a non-significant difference between tolerant and sensitive genotypes. On the basis of published results, there are still some questions about the ability of methionine synthase to distinguish tolerant or sensitive genotypes. Methionine synthase catalyzes biosynthesis of methionine, which is not only a protein amino acid, but also a precursor of S-adenosylmethionine (SAM). S-adenosylmethionine, and the S-methylated form of methionine, not only represents a universal methyl donor in plant cells, it also functions as a precursor of several stressrelated compounds including polyamines (spermine, spermidine, putrescine), ethylene, vitamin $\mathrm{H}$ (biotin), and phytosiderophores (polymers derived from non-protein amino acids deoxymugineic acid and mugineic acid involved in Fe uptake). Possible alterations in phytosiderophore biosynthesis are indicated by alterations in one enzyme of the Yang cycle, methylthioribose kinase like-1 (ssp 6513, cluster 2). Changes in methionine synthase and SAM synthase were reported in several proteomic studies dealing with abiotic stress responses (Yan et al., 2006; Vítámvás et al., 2012; Kosová et al., 2013). Alterations in methylthioribose kinase were already described by Patterson et al. (2007) in barley roots exposed to elevated boron, and by Fercha et al. (2013) in germinating wheat seedlings exposed to salinity. It is known that free metal ions can act as catalyzers of ROS formation in plant cells. Phytochelatins bind metal ions, thus preventing ROS formation.

\section{Stress- and Defense-Related Proteins}

A total of 14 proteins including proteins with chaperone and protective functions, as well as proteins directly involved in detoxification of ROS and xenobiotics, were identified in drought-treated barley crowns. Increased levels of the formation of xenobiotics is indirectly indicated by the enhanced accumulation of several glutathione-S-transferase (GST) isoforms (ssp 6108, cluster 1-glutathione-S-transferase I, subunit, ssp 7109, cluster 2-glutathione-S-transferase 6, chloroplastic, ssp 3116, cluster 1-glutathione-S-transferase F8, chloroplastic-like), which are known to conjugate xenobiotics with glutathione, resulting in the degradation of several xenobiotics. Increases in various GST classes has been reported by several proteomic studies dealing with stress (Kawamura and Uemura, 2003; Cui et al., 2005; Vítámvás et al., 2012; Budak et al., 2013; etc.). Moreover, several other roles for GST in protein regulation via S-glutathionylation as a posttranslational modification have been reported in plants (Sappl et al., 2004; Dixon et al., 2010). Additionally, GST-catalyzed S-glutathionylation has also been reported for intermediates of several plant secondary metabolites such as tetrapyrroles, quercetin, glucosinolates, etc. (Dixon et al., 2010). Glutathione peroxidase (GPX; ssp 7006, cluster 4) catalyzes the reduction of peroxides and has cytoplasmic and membrane-associated forms. GPX belongs to the ROS scavenging enzymes; an increase in several ROS scavenging enzymes has been reported in most all the proteomic studies dealing with plant stress response, since imbalances in energy metabolism during stress treatments are associated with the enhanced risk of oxidative stress (Kosová et al., 2011; Vítámvás et al., 2012).

Protein spot 114 (cluster 3) was identified as heme-binding protein 2 (SOUL protein superfamily) involved in tetrapyrrole metabolism. In Arabidopsis thaliana, heme-binding protein TSPO is known to bind tetrapyrroles, and its dynamics of degradation seems to be affected by the level of deltaaminolevulinic acid and by abscisic acid. TSPO was found to attenuate plant cell porphyria by delta-aminolevulinic acid levels and the accumulation of tetrapyrroles (Vanhee et al., 2011). Therefore, our results also indicate the attenuation of porphyria in Amulet due to increase of heme-binding protein 2, deltaaminolevulinic acid dehydratase, and GSTs.

Cellular dehydration caused by decreased SWC induces the accumulation of several proteins with protective functions; these include hydrophilic LEA proteins (ssp 401, cluster 4-Late embryogenesis abundant protein Lea14-A), and proteins related to the heat shock protein (HSP) family (ssp 803, cluster 3cytosolic HSP90) with a chaperone function. The increased accumulation of hydrophilic LEA proteins, chaperones, and HSP 
was reported in several proteomic studies (Caruso et al., 2008; Sarhadi et al., 2010; Kang et al., 2012; Budak et al., 2013; Kosová et al., 2013; Xu et al., 2013). However, some HSPs were also found to be decreased under abiotic stress treatment (e.g., HSP90 in cold-treated samples in Vítámvás et al., 2012). WendelboeNelson and Morris (2012) and Ashoub et al. (2013) found a higher accumulation of HSP70 in tolerant genotypes of barley. Moreover, the opposite trends of obtained results compared to previous results on cold-acclimated cereals (Vítámvás et al., 2012; Hlaváčková et al., 2013; Kosová et al., 2013) in HSP90 (ssp 803; increase vs. decrease) and HSP70 (ssp 3804; decrease vs. increase), respectively, together with a decrease in the accumulation of cold shock protein (ssp 3006) could indicate a specific plant response to different abiotic stresses.

Protein spot 1119 (cluster 3) was identified as chitinase II, and revealed an increase under D1 with respect to the control. Chitinases belong to several classes of pathogenesis-related (PR) proteins including PR-3, 4, 8, and 11 classes (Edreva, 2005). Not only was an increase in chitinase accumulation found in cereals exposed to fungal pathogens (Yang et al., 2010; Eggert et al., 2011), but also exposed to several abiotic stresses such as cold (Sarhadi et al., 2010), salinity (Witzel et al., 2014), and others. Protein spot 8006 was identified as a PR17c precursor. An interaction with effector proteins secreted by fungal pathogens such as barley powdery mildew has been reported for PR17c in barley; however, the molecular function of PR17 proteins still remains to be well characterized (Zhang et al., 2012). Recently, PR17 was found to be increased in salt-treated barley (Witzel et al., 2014), which underlines our finding that this protein is also responsive to abiotic stress.

Protein spot 4303 (cluster 3) was identified as ricin B lectin 2 , and it revealed an increase upon drought with respect to the control. Increased accumulation of ricin B lectin 2 was also found in the crowns of winter barley (Hlaváčková et al., 2013) and winter wheat (Kosová et al., 2013) exposed to cold.

Increased protein accumulation of $\mathrm{r} 40 \mathrm{c} 1$ (ssp 8201, cluster 3) is supported by other results in drought-treated barley cultivars with contrasting drought tolerances. Protein $\mathrm{r} 40 \mathrm{cl}$ was found to have constant level in the drought-tolerant barley cv. Basrah, while being stress increased in the roots of the susceptible cv. GP (Wendelboe-Nelson and Morris, 2012). Therefore, the trend obtained in the accumulation of $\mathrm{r} 40 \mathrm{c} 1$ supports the hypothesis that Amulet could be ranked as a genotype sensitive to drought. Moreover, an increased dephosphorylation was found in the putative $\mathrm{r} 40 \mathrm{c} 1$ protein in drought-treated rice (Ke et al., 2009).

\section{Phytohormone Metabolism}

IAA-amino acid hydrolase ILR1-like protein 1 (ssp 3401, cluster 6) catalyzes a reversible IAA inactivation. Certain IAA-amino acid conjugates inhibit root elongation and therefore, the decrease of the protein revealed upon drought indicates an increase in root development (LeClere et al., 2002).

\section{Flavonoid Metabolism}

Flavonoids represent a group of secondary plant metabolites containing at least two phenolic rings in their molecules. Flavonoids display several antioxidant and antimicrobial functions; thus, playing an important role in the plant stress response. However, in our study, the enzymes of flavonoid metabolism showed a decrease after drought treatments but flavoprotein wrbA-like isoform 1 (ssp 7110, cluster 2). Flavonoid biosynthesis in plants is realized from malonyl-CoA via the phenylpropanoid pathway to yield tricetin. Tricetin is then sequentially O-methylated by tricin synthase (ssp 112, cluster 1 ), using SAM as a methyl donor to yield tricin. The decrease of isoflavone reductase (ssp 1213, cluster 6) under drought treatments is quite interesting since isoflavone reductase is a $\mathrm{NADPH}$-dependent enzyme involved in the biosynthesis of defense-related isoflavonoid phytoalexins (Oommen et al., 1994). To our knowledge, no proteome study of drought-treated barley that revealed differential accumulation of flavonoid metabolism enzymes was published. However, some studies revealed differential changes in these proteins under salt treatment in plants. Flavone-O-methyltransferase was reported to be decreased upon salinity, with respect to the control, in germinating wheat seedlings by Fercha et al. (2014). An increase in isoflavone reductase was reported in salt-treated pea (Kav et al., 2004).

\section{Transport and Cytoskeleton-Related Proteins}

Annexin (ssp 8202, cluster 1) is a soluble protein that interacts with plasma membrane phospholipids. Monomeric annexins can form oligomeric channels enabling ion transport through plasma membrane, and they are also involved in vesicular trafficking and calcium signaling via MAPK cascade (for a review, see Laohavisit and Davies, 2011). An increase in annexin abundance was found also in salt-treated potato (Aghaei et al., 2008) and tomato (Manaa et al., 2011) plants, indicating their role in abiotic stress signaling.

Protein spot ssp 8708 (cluster 7) is identified as dynaminrelated protein $5 \mathrm{~A}$-like protein, which belongs to the dynamin $\mathrm{M}$ family. Plant dynamins are GTPases, which are involved in clathrin-mediated endocytosis process, as well as in vesicle transport between TGN and the plasma membrane. They also form a ring in the plant plastid division process; thus, the results could indicate reduced plant cell division (Bednarek and Backues, 2010). However, up to now, no differential protein changes in cereal dynamin were published in drought treated plants.

Chloroplastic protein TOC75 (ssp 8801, cluster 6) is a part of the TOC transmembrane channel in the outer chloroplast membrane. TOC75 is directly involved in protein-protein interaction and transport (Andrès et al., 2010). In our study, the protein level of TOC75 was found to decrease upon drought with respect to the control, which corresponds to the decrease in OEE proteins as components of photosystem II when observed under stress.

\section{Quantitative Changes between Drought Conditions}

Not only were differences found in physiological parameters and in the density of protein spot accumulations between drought and control conditions, but also between both drought conditions. The drought treatments were clearly distinguished 
at the level of cellular dehydration (WSD and OP values); however, $\Delta^{13} \mathrm{C}$ and DHN5 relative accumulation did not reveal significant differences between the two treatments. Nonetheless, the analyses of each protein spot density should reveal detailed information about plant response to abiotic stress conditions. Based on revealed differential changes in identified proteins, it could be hypothesized that the two drought treatments differed in their intensity, which has been mirrored with some components of energy metabolism (glycolytic enzymes, ATP metabolism) and protein degradation (proteasome subunits). However, with regards to the D2 treatment, several protein spots have shown a relatively high variability in spot density between the four biological replicates, indicating that the D2 treatment may represent a threshold between plant stress acclimation and stress damage with regard to the intensity of stress (e.g., an increase in spot 119 identified as proteasome subunit beta; or a decrease in spot 205 identified as chloroplast OEE1 protein, under D2 with respect to $\mathrm{D} 1$ treatments). Thus, the different biological processes under severe stress conditions related to plant damage or exhaustion could influence the proteome profile of D2 compared to D1. Therefore, different trends in the accumulation of a few protein spots were obtained (e.g., 2,3-bisphosphoglycerateindependent phosphoglycerate mutase-like, ssp 4708). However, the fact that most of protein spots showed the same trends of protein accumulation compared to control conditions, with higher significant differences in D2 than in D1 compared to the C (71 and 50, respectively), indicated that for plant survival careful regulation of the same biological processes and pathways are needed in both stress conditions.

\section{Conclusions}

Due to precise quantification of proteome changes by analysis of 2D-DIGE gels, we were able to determine 105 differently accumulated spots, and 76 of these were successfully identified. Until now, no other barley-drought proteome study had analyzed such a large number of protein spots. The study on drought response in the spring barley cv. Amulet has revealed that both drought treatments profoundly affected plant growth and development (changes in glycine-rich RNAbinding proteins, cell division cycle protein 48-like, gibberellin receptor GID1L2, translation initiation factor eIF5A) as well as plant energy metabolism. An enhanced need for available energy resources during the acclimation to stress conditions is indicated by profound changes in ATP metabolism as a resource of macroergic phosphate bonds. However, an enhanced risk of oxidative stress, as a consequence of imbalances in energy metabolism, leads to a downregulation of aerobic metabolism (photosynthesis, Krebs (TCA) cycle, mitochondrial electron transport chain) with respect to anaerobic metabolism (glycolysis, alcoholic fermentation). An increased risk of protein damage leads to an increase in several subunits of the proteasome complex and several protective proteins (cold shock protein, LEA-14A). Moreover, the metabolism of several stress-related metabolites (SAM metabolism-SAM as a precursor of polyamines, ethylene, phytosiderophores; flavonoid metabolism-flavonoids as protective pigments (anthocyanins) and cofactors of electron transport chain components) were significantly affected. In addition, the abundances of several proteins involved in cytoskeleton organization, protein and ion transport, etc., were affected by drought. Analysis of the obtained proteome changes demonstrated the possibility of the proteomics method used (2D-DIGE) for the evaluation of plant sensitivity or tolerance to abiotic stresses (i.e., for protein phenotyping of drought plant response). The enhanced severity of the D2 treatment was also observed at the proteome level as indicated by the differential abundance of several proteins involved in energy metabolism (glycolytic enzymes, ATP metabolism) and protein degradation (proteasome subunits); this was also validated on the physiological level (WSD and OP). Moreover, the high variability in the relative protein abundance (e.g., ssp 7109, GST6) between the four biological replicates in D2 treatment indicates an increased imbalance in cellular homeostasis in the D2 treatment, indicating a threshold between drought acclimation and damage under D2 conditions. Therefore, the wider comparison of protein abundances between other studies and ours (especially ssp 205, $401,803,2303,3008,4501,7403,8201$, and 8201) focused on barley drought-induced proteome changes (Wendelboe-Nelson and Morris, 2012; Ashoub et al., 2013; Ghabooli et al., 2013; Kausar et al., 2013) can prove Amulet sensitivity to drought solely on the results of proteomic analysis.

For future protein phenotyping for drought plant response, the repeating and significant trends in protein spot accumulation under both drought conditions should be interesting to test. From the four protein spots that revealed a continuous significant increase under C, D1, and D2 treatments, only two spots (ssp 4614-UDP-glucose 6-dehydrogenase, cluster 3; and ssp 7006glutathione peroxidase, cluster 3 ) were identified. However, all four (i.e., also ssp 7001 and 8104) could be good candidates for testing of their protein phenotyping capacity together with proteins that were significantly distinguished in both drought treatments.

\section{Acknowledgments}

This work was supported by the Ministry of Agriculture of the Czech Republic (QJ1310055 and MZE RO0415) and by the Ministry of Education, Youth and Sports (LD14064 and LD14087 as parts of COST Actions FA1204 and FA1208, respectively). We thank Sébastien Planchon for his technical support in protein identifications. We thank Dr. Peter Lemkin, PhD. for English revision of the manuscript.

\section{Supplementary Material}

The Supplementary Material for this article can be found online at: http://journal.frontiersin.org/article/10.3389/fpls.2015. 00479 


\section{References}

Aghaei, K., Ehsanpour, A. K., and Komatsu, S. (2008). Proteome analysis of potato under salt stress. J. Proteome Res. 7, 4858-4868. doi: 10.1021/pr800460y

Andrès, C., Agne, B., and Kessler, F. (2010). The TOC complex: preprotein gateway to the chloroplast. Biochim. Biophys. Acta 1803, 715-723. doi: 10.1016/j.bbamcr.2010.03.004

Ashoub, A., Beckhaus, T., Berberich, T., Karas, M., and Brüggemann, W. (2013). Comparative analysis of barley leaf proteome as affected by drought stress. Planta 237, 771781. doi: 10.1007/s00425-012-1798-4

Bednarek, S. Y., and Backues, S. K. (2010). Plant dynamin-related protein families DRP1 and DRP2 in plant development. Biochem. Soc. Trans. 38, 797-806. doi: 10.1042/BST0380797

Budak, H., Akpinar, B. A., Unver, T., and Turktas, M. (2013). Proteome changes in wild and modern wheat leaves upon drought stress by two-dimensional electrophoresis and nanoLC-ESI-MS/MS. Plant Mol. Biol. 83, 89-103. doi: 10.1007/s11103-013-0024-5

Caraux, G., and Pinloche, S. (2005). Permutmatrix: a graphical environment to arrange gene expression profiles in optimal linear order. Bioinformatics 21, 1280-1281. doi: 10.1093/bioinformatics/btil41

Caruso, G., Cavaliere, C., Guarino, C., Gubbiotti, R., Foglia, P., and Laganà, A. (2008). Identification of changes in Triticum durum L. leaf proteome in response to salt stress by two-dimensional electrophoresis and MALDI-TOF mass spectrometry. Anal. Bioanal. Chem. 391, 381-390. doi: 10.1007/s00216008-2008-x

Chao, W. S., Gu, Y. Q., Pautot, V., Bray, E. A., and Walling, L. L. (1999). Leucine aminopeptidase RNAs, proteins, and activities increase in response to water deficit. Plant Physiol. 120, 979-992.

Cui, S., Huang, F., Wang, J., Ma, X., Cheng, Y., and Liu, J. (2005). A proteomic analysis of cold stres responses in rice seedlings. Proteomics 5, 3162-3172. doi: 10.1002/pmic.200401148

Dixon, D. P., Skipsey, M., and Edwards, R. (2010). Roles for glutathione transferases in plant secondary metabolism. Phytochemistry 71, 338-350. doi: 10.1016/j.phytochem.2009.12.012

Edreva, A. (2005). Pathogenesis-related proteins: research progress in the last 15 years. Gen. Appl. Plant Physiol. 31, 105-124. Available online at: http://www.bio21.bas.bg/ipp/gapbfiles/v-31/05_1-2_105-124.pdf

Eggert, K., Zörb, C., Mühling, K. H., and Pawelzik, E. (2011). Proteome analysis of Fusarium infection in emmer grains (Triticum dicoccum). Plant Pathol. 60, 918-928. doi: 10.1111/j.1365-3059.2011.02442.x

Erban, T., and Hubert, J. (2015). Two-dimensional gel proteomics analysis of Dermatophagoides farinae feces. Exp. Appl. Acarol. 65, 73-87. doi: 10.1007/s10493-014-9848-1

Fatehi, F., Hosseinzadeh, A., Alizadeh, H., Brimavandi, T., and Struik, P. C. (2012). The proteome response of salt-resistant and salt-sensitive barley genotypes to long-term salinity stress. Mol. Biol. Rep. 39, 6387-6397. doi: 10.1007/s11033012-1460-z

Fercha, A., Capriotti, A. L., Caruso, G., Cavaliere, C., Gherroucha, H., Samperi, R., et al. (2013). Gel-free proteomics reveals potential biomarkers of priminginduced salt tolerance in durum wheat. J. Proteomics 91, 486-499. doi: 10.1016/j.jprot.2013.08.010

Fercha, A., Capriotti, A. L., Caruso, G., Cavaliere, C., Samperi, R., Stampachiacchiere, S., et al. (2014). Comparative analysis of metabolic proteome variation in ascorbate-primed and unprimed wheat seeds during germination under salt stress. J. Proteomics 108, 238-257. doi: 10.1016/j.jprot.2014.04.040

Ford, K. L., Cassin, A., and Bacic, A. (2011). Quantitative proteomic analysis of wheat cultivars with differing drought stress tolerance. Front. Plant Sci. 2:44. doi: $10.3389 /$ fpls.2011.00044

Ganeshan, S., Vítámvás, P., Fowler, D. B., and Chibbar, R. N. (2008). Quantitative expression analysis of selected COR genes reveals their differential expression in leaf and crown tissues of wheat (Triticum aestivum L.) during an extended low temperature acclimation regimen. J. Exp. Bot. 59, 2393-2402. doi: $10.1093 / \mathrm{jxb} / \mathrm{ern} 112$

Ghabooli, M., Khatabi, B., Ahmadi, F. S., Sepehri, M., Mizraei, M., Amirkhani, A., et al. (2013). Proteomics study reveals the molecular mechanisms underlying water stress tolerance induced by Piriformospora indica in barley. J. Proteomics 94, 289-301.doi: 10.1016/j.jprot.2013.09.017
Gharechahi, J., Alizadeh, H., RezaNaghavi, M., and Sharifi, G. (2014). A proteomic analysis to identify cold acclimation associated proteins in wild wheat (Triticum urartu L.). Mol. Biol. Rep. 41, 3897-3905. doi: 10.1007/s11033-014$3257-8$

Gong, Z., Dong, C. H., Lee, H., Zhu, J., Xiong, L., Gong, D., et al. (2005). A DEAD box RNA helicase is essential for mRNA export and important for development and stress responses in Arabidopsis. Plant Cell 17, 256-267. doi: 10.1105/tpc.104.027557

Guo, P. G., Baum, M., Grando, S., Ceccarelli, S., Bai, G. H., Li, R. H., et al. (2009). Differentially expressed genes between drought-tolerant and drought-sensitive barley genotypes in response to drought stress during the reproductive stage. J. Exp. Bot. 60, 3531-3544. doi: 10.1093/jxb/erp194

Hlaváčková, I., Vítámvás, P., Šantrùèek, J., Kosová, K., Zelenková, S., Prášil, I. T., et al. (2013). Proteins involved in distinct phases of cold hardening process in frost resistant winter barley (Hordeum vulgare L.) cv. Luxor. Int. J. Mol. Sci. 44, 8000-8024. doi: 10.3390/ijms14048000

Holková, L., Prášil, I. T., Bradáèová, M., Vítámvás, P., and Chloupek, O. (2009). Screening for frost tolerance in wheat using the expression of dehydrin genes Wcs 120 and Wdhn 13 at $17^{\circ} \mathrm{C}$. Plant Breed. 128, 420-422. doi: 10.1111/j.14390523.2008.01606.x

Kang, G., Li, G., Xu, W., Peng, X., Han, Q., Zhu, Y., et al. (2012). Proteomics reveals the effects of salicylic acid on growth and tolerance to subsequent drought stress in wheat. J. Proteome Res. 11, 6066-6079. doi: 10.1021/pr300728y

Kausar, R., Arshad, M., Shahzad, A., and Komatsu, S. (2013). Proteomics analysis of sensitive and tolerant barley genotypes under drought stress. Amino Acids 44, 345-359. doi: 10.1007/s00726-012-1338-3

Kav, N. N. V., Srivastava, S., Goonewardene, L., and Blade, S. F. (2004). Proteomelevel changes in the roots of Pisum sativum in response to salinity. Ann. Appl. Biol. 145, 217-230. doi: 10.1111/j.1744-7348.2004.tb00378.x

Kawamura, Y., and Uemura, M. (2003). Mass spectrometric approach for identifying putative plasma membrane proteins of Arabidopsis leaves associated with cold acclimation. Plant J. 36, 141-154. doi: 10.1046/j.1365313X.2003.01864.X

Ke, Y., Han, G., He, H., and Li, J. (2009). Differential regulation of proteins and phosphoproteins in rice under drought stress. Biochem. Biophys. Res. Com. 379, 133-138. doi: 10.1016/j.bbrc.2008.12.067

Kosová, K., Prášil, I. T., Prášilová, P., Vítámvás, P., and Chrpová, J. (2010). The development of frost tolerance and DHN5 protein accumulation in barley (Hordeum vulgare) doubled haploid lines derived from Atlas 68 x Igri cross during cold acclimation. J. Plant Physiol. 167, 343-350. doi: 10.1016/j.jplph.2009.09.020

Kosová, K., Prášil, I. T., and Vítámvás, P. (2008). The relationship between vernalization- and photoperiodically-regulated genes and the development of frost tolerance in wheat and barley. Biol. Plant. 52, 601-615. doi: 10.1007/s10535-008-0120-6

Kosová, K., Prášil, I. T., Vítámvás, P., Dobrev, P., Motyka, V., Floková, K., et al. (2012). Complex phytohormone responses during the cold acclimation of two wheat cultivars differing in cold tolerance, winter Samanta and spring Sandra. J. Plant Physiol. 169, 567-576. doi: 10.1016/j.jplph.2011. 12.013

Kosová, K., Vítámvás, P., Planchon, S., Renaut, J., Vanková, R., and Prášil, I. T. (2013). Proteome analysis of cold response in spring and winter wheat (Triticum aestivum) crowns reveals similarities in stress adaptation and differences in regulatory processes between the growth habits. J. Proteome Res. 12, 4830-4845. doi: $10.1021 / \mathrm{pr} 400600 \mathrm{~g}$

Kosová, K., Vítámvás, P., and Prášil, I. T. (2014). Wheat and barley dehydrins under cold, drought, and salinity-what can LEA-II proteins tell us about plant stress response? Front. Plant Sci. 5:343. doi: 10.3389/fpls.2014.00343

Kosová, K., Vítámvás, P., Prášil, I. T., and Renaut, J. (2011). Plant proteome changes under abiotic stress-contribution of proteomics studies to understanding plant stres sresponse. J. Proteomics 74, 1301-1322. doi: 10.1016/j.jprot.2011.02.006

Laemmli, U. K. (1970). Cleavage of structural proteins during the assembly of the head of the bacteriophage T4. Nature 277, 680-685. doi: 10.1038/227680a0

Laohavisit, A., and Davies, J. M. (2011). Annexins. Tansley review. New Phytol. 189, 40-53. doi: 10.1111/j.1469-8137.2010.03533.x

Larcher, W. (2003). Physiological Plant Ecology. 4th Edn. Berlin; Heidelberg: Springer Verlag. 
Lawlor, D. W. (2013). Genetic engineering to improve plant performance under drought: physiological evaluation of achievements, limitations, and possibilities. J. Exp. Bot. 64, 83-108. doi: 10.1093/jxb/ers326

LeClere, S., Tellez, R., Rampey, R. A., Matsuda, S. P. T., and Bartel, B. (2002). Characterization of a family of IAA-amino acid conjugate hydrolases from Arabidopsis. J. Biol. Chem. 277, 20446-20452. doi: 10.1074/jbc.M1119 55200

Levitt, J. (1980). Responses of Plants to Environmental Stress. Vol. II Water, Radiation, Salt, and Other Stresses. 2nd Edn. New York, NY: Academic Press.

Manaa, A., Ben Ahmed, H., Valot, B., Bouchet, J. P., Aschi-Smiti, S., Causse, M., et al. (2011). Salt and genotype impact on plant physiology and root proteome variations in tomato. J. Exp. Bot. 62, 2797-2813. doi: 10.1093/jxb/erq460

O'Farrell, P. H. (1975). High resolution two-dimensional electrophoresis of proteins. J. Biol. Chem. 250, 4007-4021.

Oommen, A., Dixon, R. A., and Paiva, N. L. (1994). The elicitor-inducible alfalafa isoflavone reductase promoter confers different patterns of developmental expression in homologous and heterologous transgenic plants. Plant Cell 6, 1789-1803.

Patterson, J., Ford, K., Cassin, A., Natera, S., and Bacic, A. (2007). Increased abundance of proteins involved in phytosiderophore production in boron-tolerant barley. Plant Physiol. 144, 1612-1631. doi: 10.1104/pp.107. 096388

Rampitsch, C., Bykova, N. V., McCallum, B., Beimcik, E., and Ens, W. (2006). Analysis of the wheat and Puccinia triticina (leaf rust) proteomes during a susceptible host-pathogen interaction. Proteomics 6, 1897-1907. doi: 10.1002/pmic.200500351

Rasoulnia, A., Bihamta, M. R., Peyghambari, S. A., Alizadeh, H., and Rahnama, A. (2011). Proteomic response of barley leaves to salinity. Mol. Biol. Rep. 38, 5055-5063. doi: 10.1007/s11033-010-0651-8

Rinalducci, S., Egidi, K. G., Mahfoozi, S., Godehkahriz, S. J., and Zolla, L. (2011). The influence of temperature on plant development in a vernalizationrequiring winter wheat:A2-DE based proteomic investigation. J. Proteomics 74, 643-659. doi: 10.1016/j.jprot.2011.02.005

Sappl, P. G., Oñate-Sánchez, L., Singh, K. B., and Millar, A. H. (2004). Proteomic analysis of glutathione $S$-transferases of Arabidopsis thaliana reveals differential salicylic acid-induced expression of the plant-specific phi and tau classes. Plant Mol. Biol. 54, 205-219. doi: 10.1023/B:PLAN.0000028786.57439.b3

Sarhadi, E., Mahfoozi, S., Hosseini, S. A., and Salekdeh, G. H. (2010). Cold accliamtion proteome analysis reveals close link between upregulation of lowtemperature associated proteins and vernalization fulfillment. J. Proteome Res. 9, 5658-5667. doi: 10.1021/pr100475r

Skadsen, R. W., Sathish, P., and Kaeppler, H. F. (2000). Expression of thaumatinlike permatin PR-5 genes switches from the ovary wall to the aleurone in developing barley and oat seeds. Plant Sci. 156, 11-22. doi: 10.1016/S01689452(00)00226-0

Talame, V., Ozturk, N. Z., Bohnert, H. J., and Tuberosa, R. (2007). Barley transcript profiles under dehydration shock and drought stress treatments: a comparative analysis. J. Exp. Bot 58, 229-240. doi: 10.1093/jxb/erl163

Tanino, K. K., and McKersie, B. D. (1985). Injury within the crown of winterwheat seedlings after freezing and icing stress. Can. J. Bot. 63, 432-436. doi: 10.1139/b85-053

The International Barley Genome Sequencing Consortium. (2012). A physical, genetic and functional sequence assembly of the barley genome. Nature 491, 711-717. doi: 10.1038/nature11543

Thompson, J. E., Hopkins, M. T., Taylor, C., and Wang, T. W. (2004). Regulation of senescence by eukaryotic translation initiation factor 5A: implications for plant growth and development. Trends Plant Sci. 9, 174-179. doi: 10.1016/j.tplants.2004.02.008

Tommasini, L., Svensson, J. T., Rodriguez, E. M., Wahid, A., Malatrasi, M., Kato, K., et al. (2008). Dehydrin gene expression provides an indicator of low temperature and drought stress: transcriptome-based analysis of barley (Hordeum vulgare L.). Funct. Integr. Genomics 8, 387-405. doi: 10.1007/s10142008-0081-z
Ueda, A., Kathiresan, A., Inada, M., Narita, Y., Nakamura, T., Shi, W. M., et al. (2004). Osmotic stress in barley regulate expression of a different set of genes than salt stress does. J. Exp. Bot. 55, 2213-2218. doi: 10.1093/jxb/erh242

Ueguchi-Tanaka, M., Nakajima, M., Ashikari, M., and Matsuoka, M. (2007). Gibberellin receptor and its role in gibberellin signaling in plants. Annu. Rev. Plant Biol. 58, 183-198. doi: 10.1146/annurev.arplant.58.032806.103830

Vanhee, C., Zapotoczny, G., Masquelier, D., Ghislain, M., and Batoko, H. (2011). The Arabidopsis multistress regulator TSPO is a heme binding membrane protein and a potential scavenger of porphyrins via an autophagy-dependent degradation mechanism. Plant Cell 23, 785-805. doi: 10.1105/tpc.110. 081570

Vítámvás, P., Kosovaì, K., Praišilovaì, P., and Praišil, I. T. (2010). Accumulation of WCS120 protein in wheat cultivars grown at 9 or $17{ }^{\circ} \mathrm{C}$ in relation to their winter survival. Plant Breed. 129, 611-616. doi: 10.1111/j.14390523.2010.01783.x

Vítámvás, P., and Prášil, I. T. (2008). WCS120 protein family and frost tolerance during cold acclimation, deacclimation and reacclimation of winter wheat. Plant Physiol. Biochem. 46, 970-976. doi: 10.1016/j.plaphy.2008.06.006

Vítámvás, P., Prášil, I. T., Kosová, K., Planchon, S., and Renaut, J. (2012). Analysis of proteome and frost tolerance in chromosome $5 \mathrm{~A}$ and $5 \mathrm{~B}$ reciprocal substitution lines between two winter wheats during long-term cold acclimation. Proteomics 12, 68-85. doi: 10.1002/pmic.201000779

Vítámvás, P., Saalbach, G., Prášil, I. T., Ėapková, V., Opatrná, J., and Jahoor, A. (2007). WCS120 protein family and proteins soluble upon boiling in cold-acclimated winter wheat. J. Plant Physiol. 164, 1197-1207. doi: 10.1016/j.jplph.2006.06.011

Wang, W., Vignani, R., Scali, M., and Cresti, M. (2006). A universal and rapid protocol for protein extraction from recalcitrant plant tissues for proteomic analysis. Electrophoresis 27, 2782-2786. doi: 10.1002/elps.200500722

Wendelboe-Nelson, C., and Morris, P. C. (2012). Proteins linked to drought tolerance revealed by DIGE analysis of drought resistant and susceptible barley varieties. Proteomics 12, 3374-3385. doi: 10.1002/pmic.201200154

Witzel, K., Matros, A., Strickert, M., Kaspar, S., Peukert, M., Mühling, K. H., et al. (2014). Salinity stress in roots of contrasting barley genotypes reveals time-distinct and genotype-specific patterns for defined proteins. Mol. Plant 7, 336-355. doi: $10.1093 / \mathrm{mp} / \mathrm{sst} 063$

Xu, J., Li, Y., Sun, J., Du, L., Zhang, Y., Yu, Q., et al. (2013). Comparative physiological and proteomic response to abrupt low temperature stress in two winter wheat cultivars differing in low temperature tolerance. Plant Biol. 15, 292-303. doi: 10.1111/j.1438-8677.2012.00639.x

Yan, S. P., Zhang, Q. Y., Tang, Z. C., Su, W. A., and Sun, W. N. (2006). Comparative proteomic analysis provides new insight into chilling stress response in rice. Mol. Cell. Proteomics 5, 484-496. doi: 10.1074/mcp.M500251-MCP200

Yang, F., Jensen, J. D., Svensson, B., Jørgensen, H. J. L., Collinge, D. B., and Finnie, C. (2010). Analysis of early events in the interaction between Fusarium graminearum and the susceptible barley (Hordeum vulgare) cultivar Scarlett. Proteomics 10, 3748-3755. doi: 10.1002/pmic.201000243

Zhang, W. J., Pedersen, C., Kwaaitaal, M., Gregersen, P. L., Mørch, S. M., Hanisch, S., et al. (2012). Interaction of barley powdery mildew effector candidate CSEP0055 with the defens protein PR17c. Mol. Plant Pathol. 13, 1110-1119. doi: 10.1111/j.1364-3703.2012.00820.x

Conflict of Interest Statement: The authors declare that the research was conducted in the absence of any commercial or financial relationships that could be construed as a potential conflict of interest.

Copyright @ 2015 Vitámvás, Urban, Škodáček, Kosová, Pitelková, Vitámvás, Renaut and Prásil. This is an open-access article distributed under the terms of the Creative Commons Attribution License (CC BY). The use, distribution or reproduction in other forums is permitted, provided the original author(s) or licensor are credited and that the original publication in this journal is cited, in accordance with accepted academic practice. No use, distribution or reproduction is permitted which does not comply with these terms. 